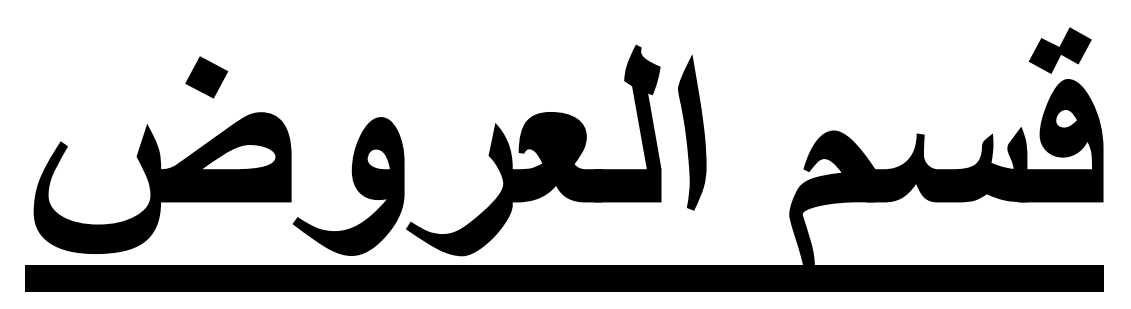

$$
\text { إشراف // اميرة ابراهيم شعبان }
$$

المدرس المساعد بقسم المكتبات والمعلومات بكلية الآداب - جامعة الاسكندرية

1 - عرض لرسالة ماجستير بعنوان : " مهارات البحث على الإنترنت لطلاب القرن الحادي و العشرين:

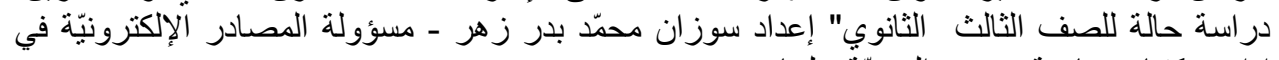

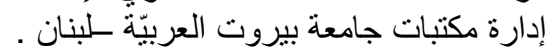

r- العرض :دور ملتقبات المبدعين في تنمية الإبداع لدى التلاميذ دراسة تجريبية في مكتبة مدرسة النيل

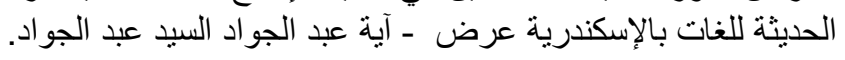

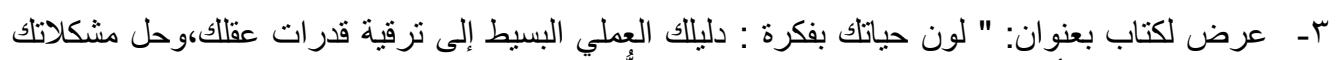

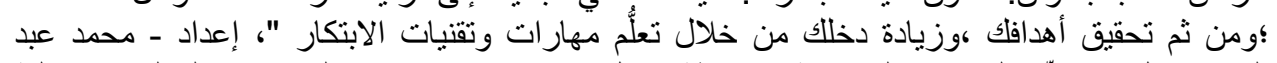

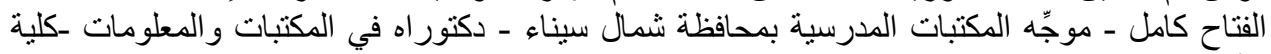




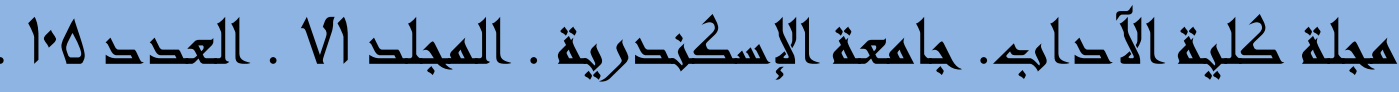

\section{العرض الاول}

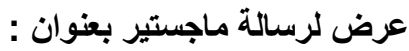 \\ " مهارات البحث على الإنترنت لطلاب القرن الحادي و العشرين: \\ دراسة حالة للصف الثالث الثانوي" '
}

إعداد

سوزان محمّل بلر زهر

مسؤولة المصادر الإلكترونيّة في إدارة مكتبات جامعة بيروت العربيّة -لبنان

Email: s.zahr@bau.edu.Ib; Ircatomar@gmail.com

تمهي⿻ :

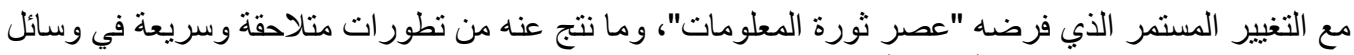

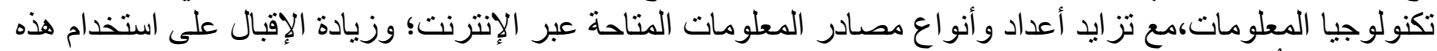

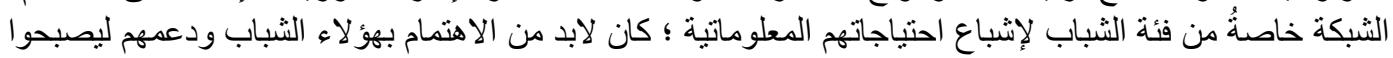
قادرين على مساعدة أنفهم في حل المشكلات المعلوماتية الخاصة بهم مدى الحئة الحباة.

أهداف الر اسة:

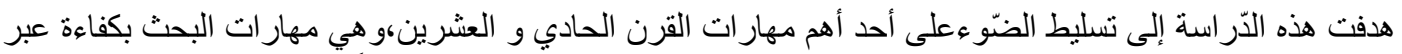

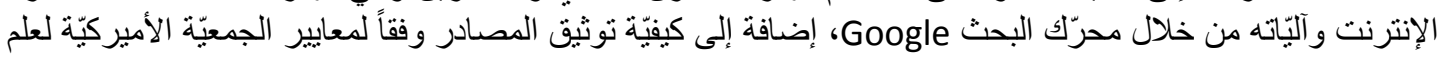

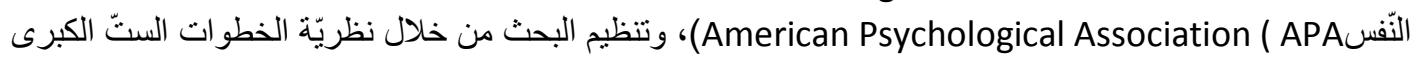

.(Big Six)

منهج الدراسة:

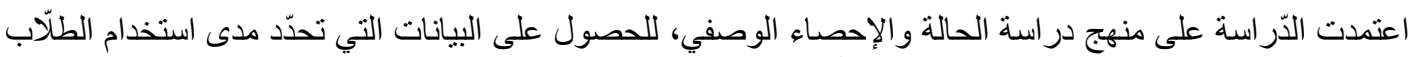

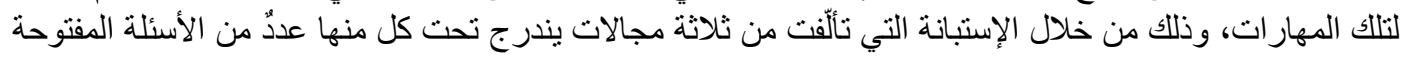
و المغلقة وفق مقياس Thurston

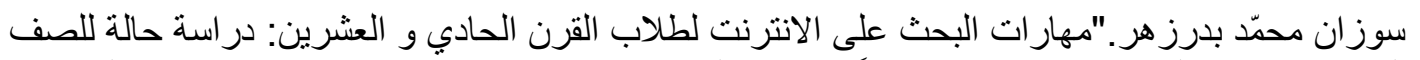

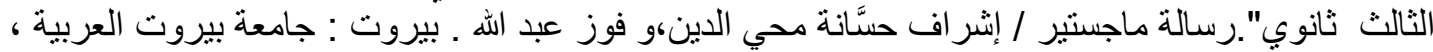

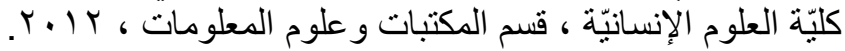




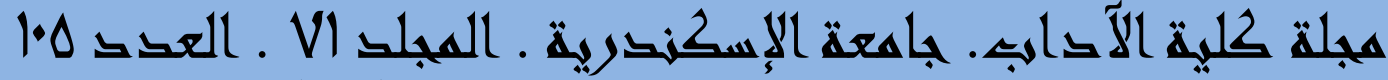

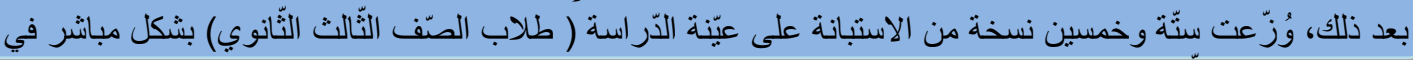

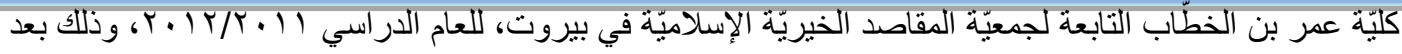

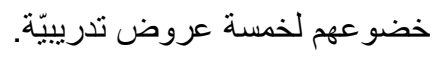

أهميّية الدّر اسة

تكمن أهميّة الدّر اسة في النّقاط الآتية:

أوّ لاً: طرح مفهوم جديد لدى طلّاب المدارس وتحديداً طلّاب الصّف الثّالث ثانوي (عبّنة البحث)، يتمنّل بإتقانهم لمهار ات

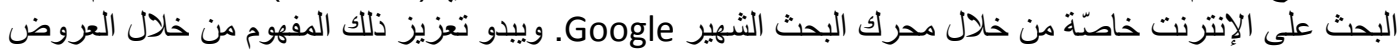
التدريبيّة.

ثانياً: تعزيز قدر ات طلاب المدارس في إجر اء أبحاثهم المدرسيّة عبر الإنترنت؛ حيث أنّ معظم الدّراسات في هذا المجال

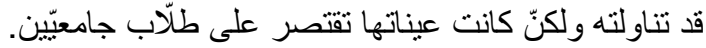

نتائج الدراسة :

أظهرت النتائج أنّ نسبة كبيرة من الطلاب قد استخدموا محرّك البحث Google وفق الإستر اتيجيّات التي تلقّّ ها، حيث

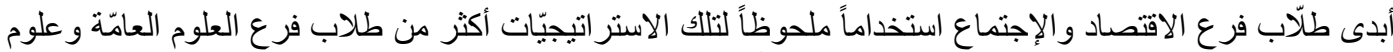
الحياة. كما تبيّن أنّ الطلاب كافّة يمتلكون سمات الإنعلّمين في القرن الحادي و العشرين ، وفيما يلي النتائج بالتفصيل:

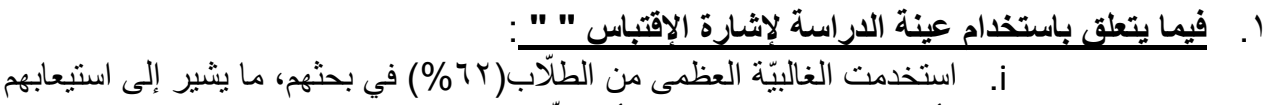

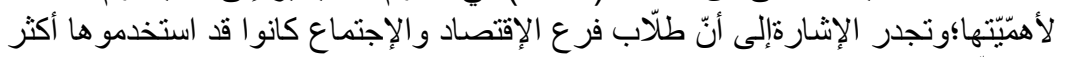

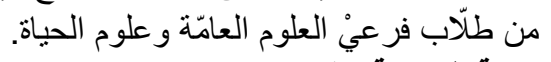

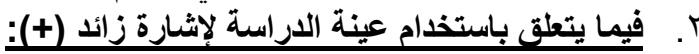

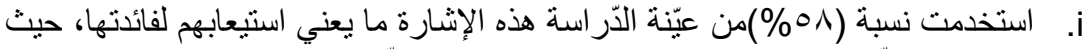

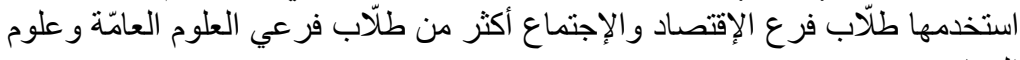

$$
\text { الحياة. }
$$

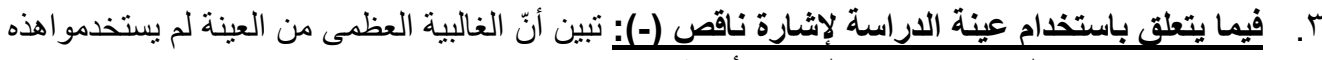

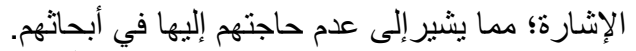

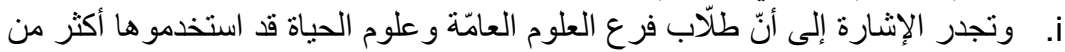

$$
\text { غير هم. }
$$

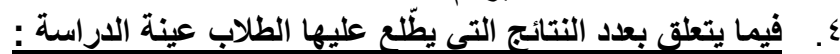

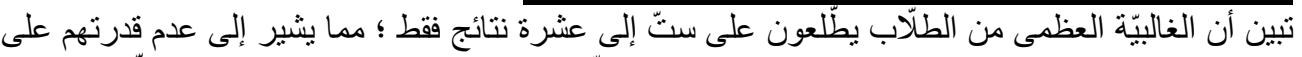

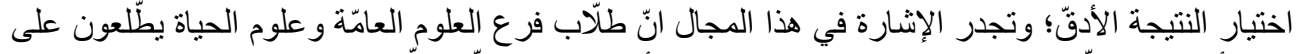

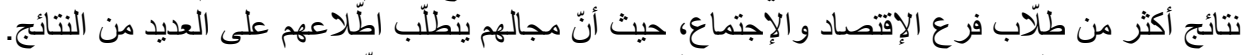

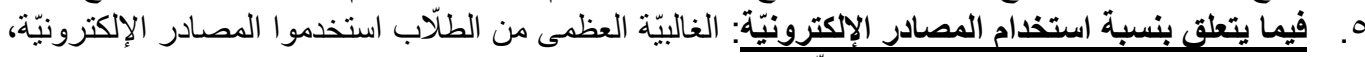

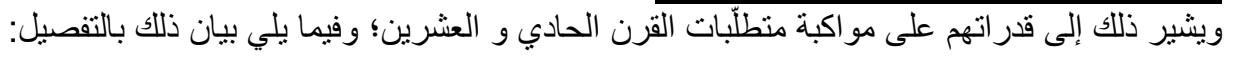

أ. استخدام البحث المتقدّم في Google

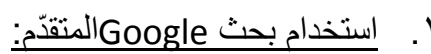

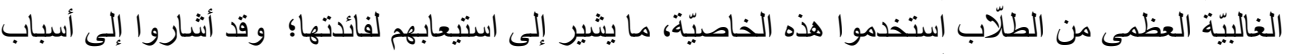

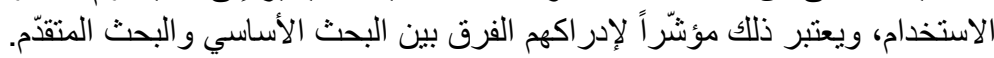

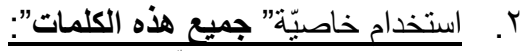

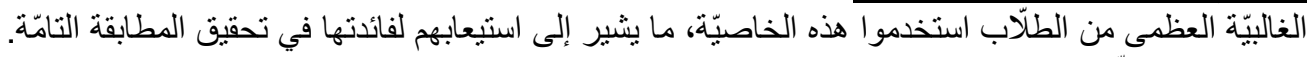
ب. استخدام خانة اللّغة:

اللغة كانت عاملاً مهمّا في أبحاث الطلّاب، إذّة يبدو ذلك من خلال النّبة الكبيرة لاستخدامها، حيث استخدمها

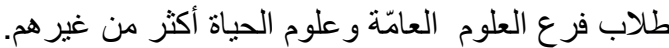

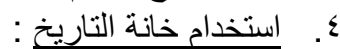

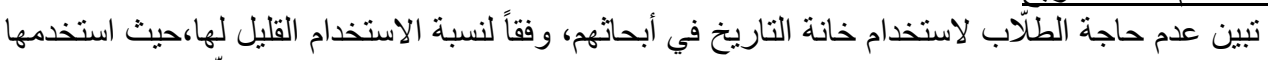

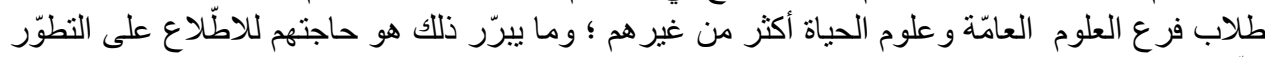

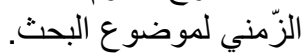

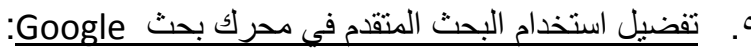




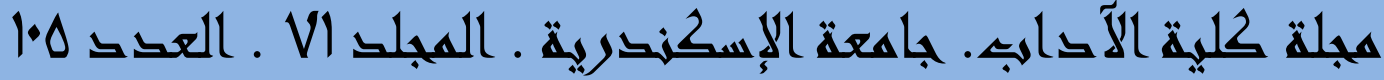

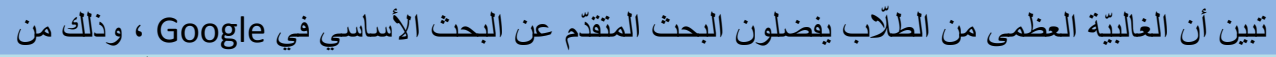

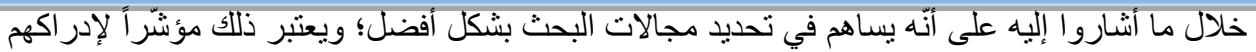

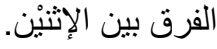

\section{ب. استخدام الباحث العلمى Google Scholar:}

لقد استخدمه نسبة قليلة من الطلّاب عينة الدراسة؛مما يشير إلى عدم معرفة الأكثرية منه بهذا الباحث.

آ. فيما يتعلق بمهارات الوعي المعلوماتي و القرن الحادي و العشرين

أ- إستخدام مو اقع التو اصل الإجتماعي:

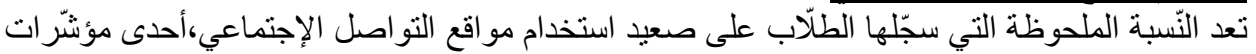
القدرة على مو اكبة متطلّبات القرن الحادي و العشرئ العين.

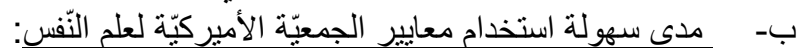

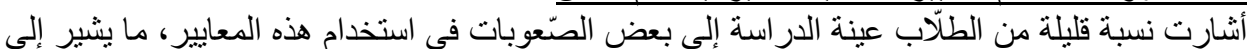

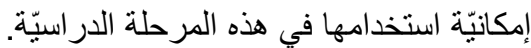

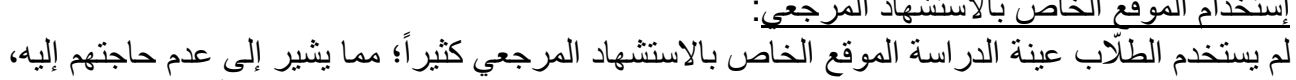
خاصّة انّهم لم يجدوا صعوبة في تطبيق معايير الاستشهاد المرجعي كما تمت الإن الإنشارة سابقاً.

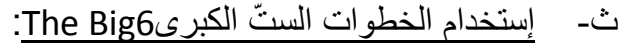

لم بستخدم الطلّاب عينة الدراسة هذه النّظريّة كثير اً ؛ و قد يعود ذلك إلى مساعدة معلَّميهم لهم في تنظيم خطوات أبحاثهر. ج- الحاجة إلى التدريب:

تبين من نتائج الدر استة ضرورة إعطاء المحاضر ات التدرييّة في مراحل در اسية سابقة.

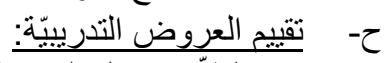
كان الطلّاب محل الدراستة قادرين على استيعاب العروض التدرييّة التي تم تقديمها لهم ؛و قد بدا ذلك من

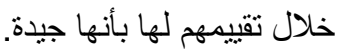

\section{توصيات الدراسة :}

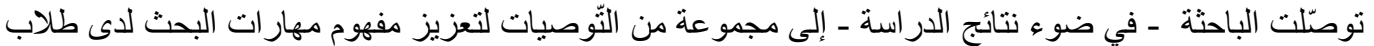

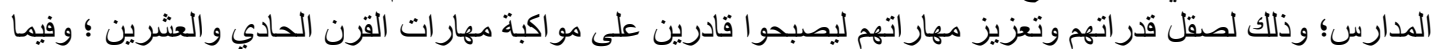

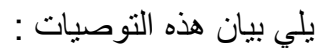

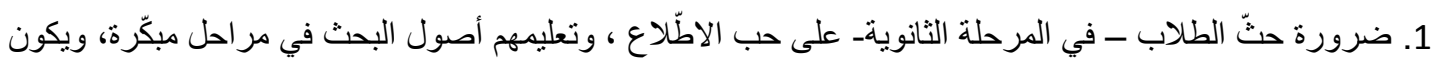

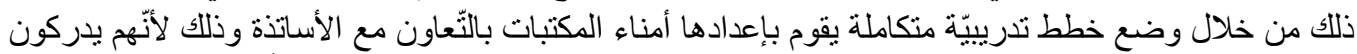

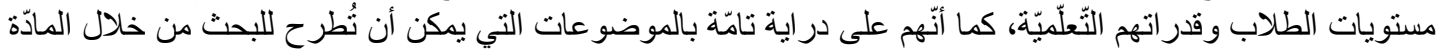
التعليميّة؛ وكذلك من خلال التّعاون مع تقنيّي المعلومات في تو عية الطلاب على الاستخدام الآمن للإنترنت لإنت

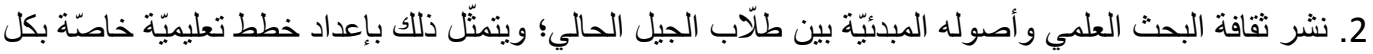

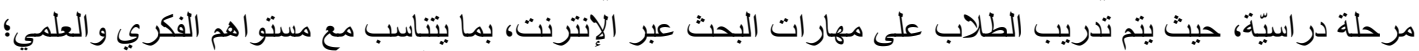

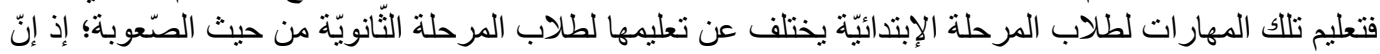

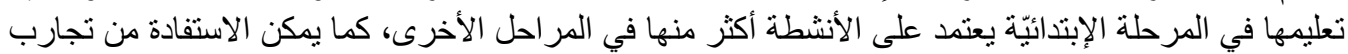

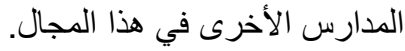

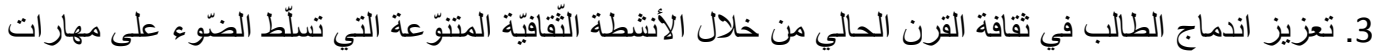

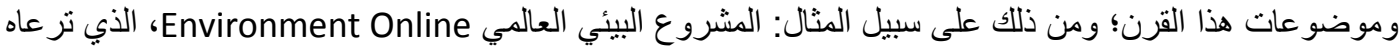
شبكة من الددارس الإفتراضيّة لتعزيز الوعي البيئي حول العالم من خلال تحديد يوم عالئي المي لئي لغرس الأثجار و حماية البيئة

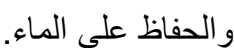

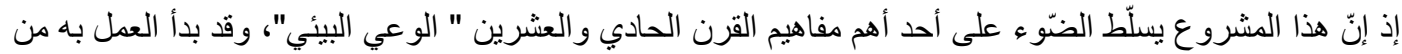

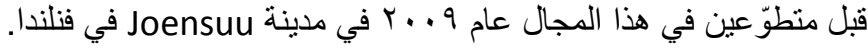

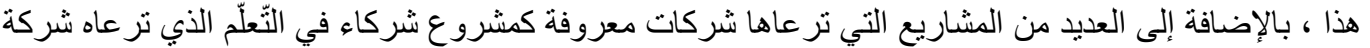

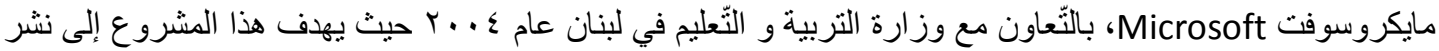

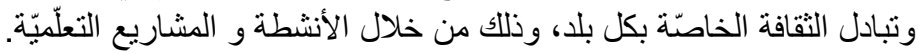




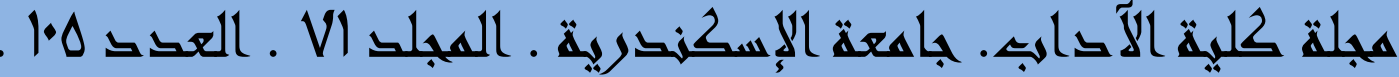

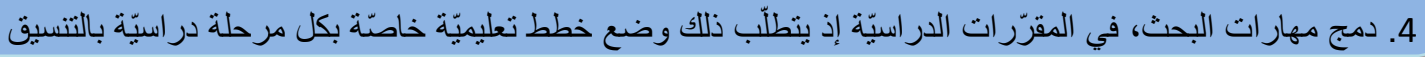

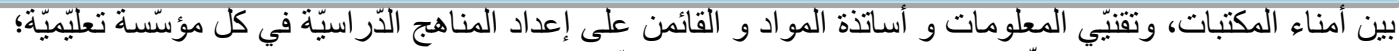

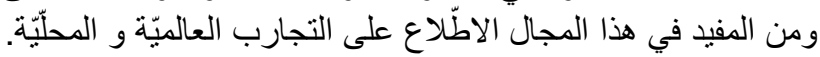

5. تطوير محرّكات بحث أكثر ملاءمة لطبيعة اللّغة العربيّة ، وذذلك من خلال تعزيز التّعاون بين التقنيّين من جهة وعلماء

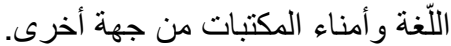

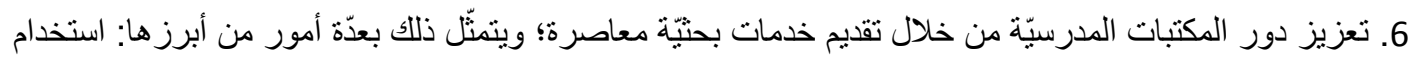

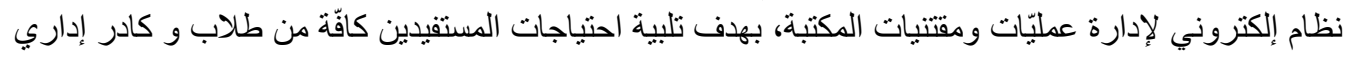
وتعليمي. و تكاد تكون أهم خدمة تقدمها المكتبة من وجهة نظر الباحثة- هي تدريب الطلاب على مهارات البحث على الانترنت،

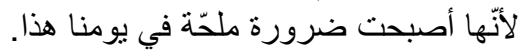
بالإضافة إلى إعداد خطط خاصّة بالأنشطة التتقيفّة المحليّة و العالميّة على مدار العام، وذلك لتعزيز اندماج الطلاب و المجتمع المدرسي في ثقافة القرن الحالي.

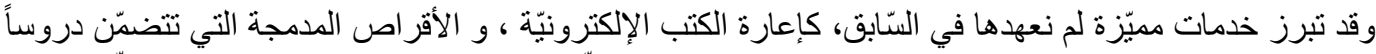

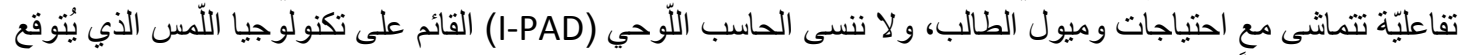

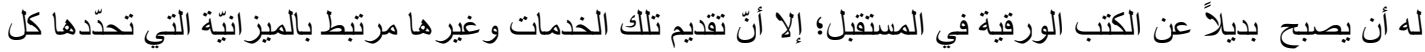
مدرسة لمكتبنها. 


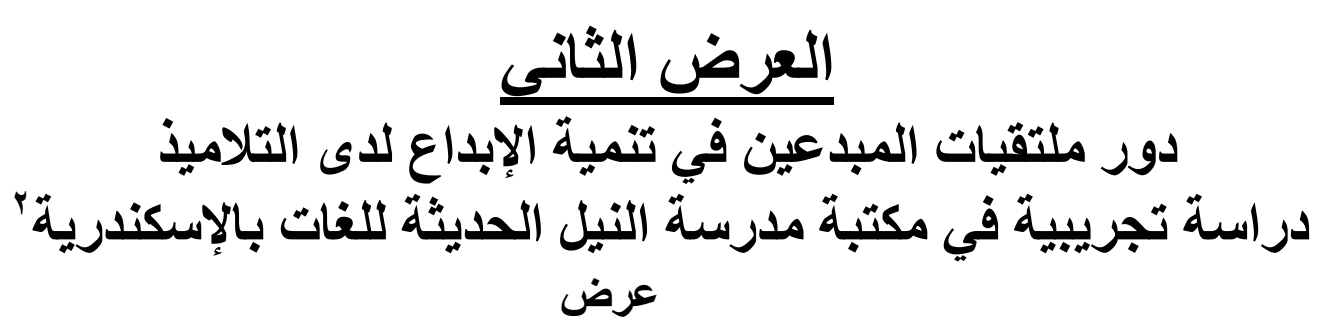

آية عبد الجواد السيد عبد الجواد

تمهيد:

تعد المكتبات من المنُشآت المؤثرة في الحياة؛ فالمعلومات هي أساس الحياة، و لا يتسنى الماتى

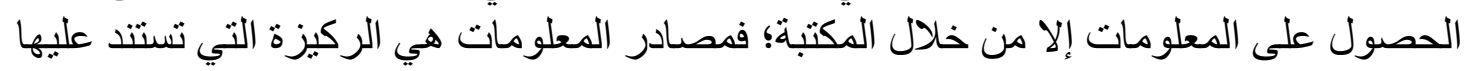

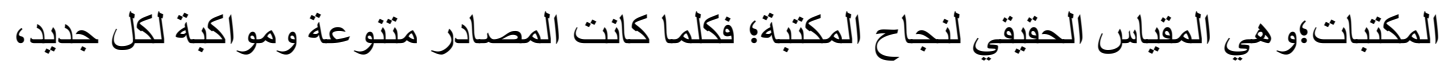

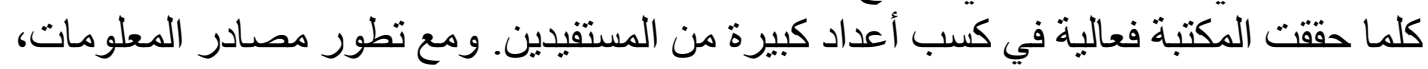

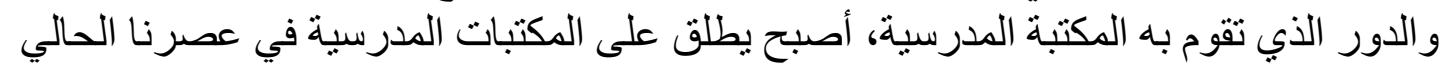

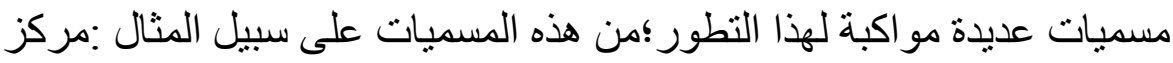

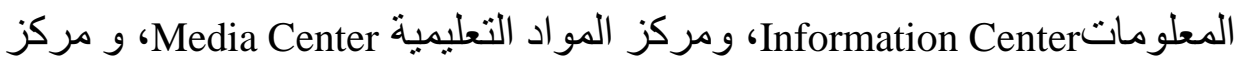

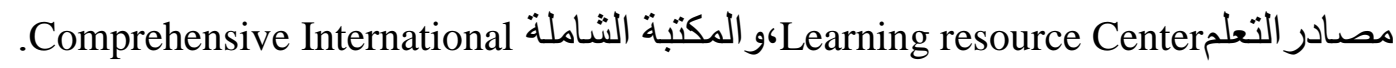

أما ملتقى المبدعين ”Makerspace“فهو أحد الإضافات التطويرية للمكتبة المدرسية ؛فهو

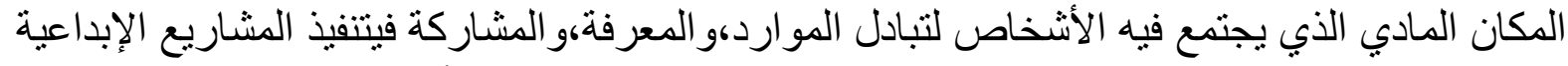

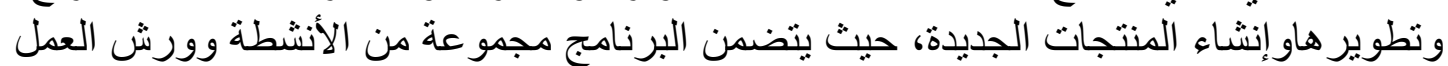

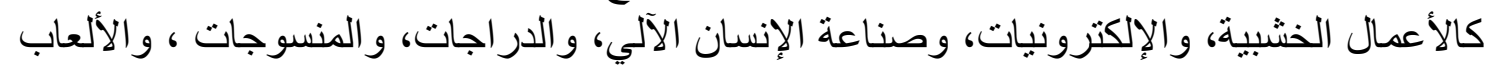

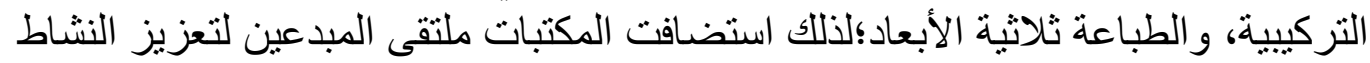

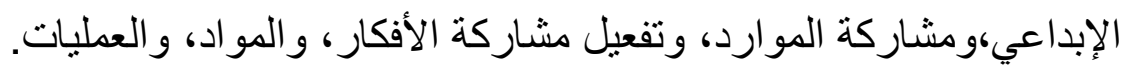

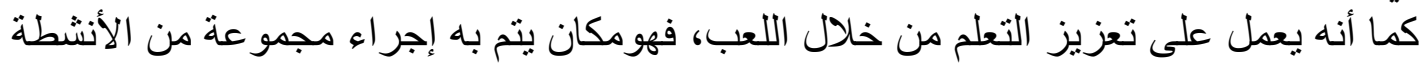

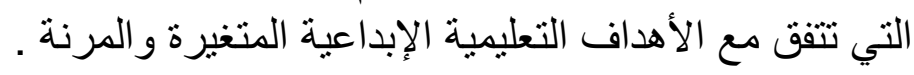

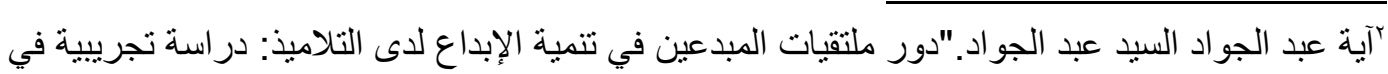

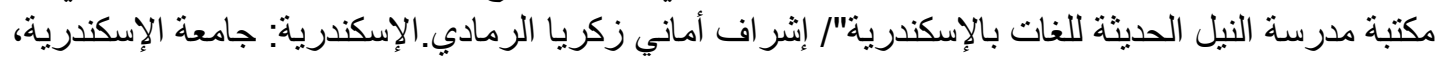




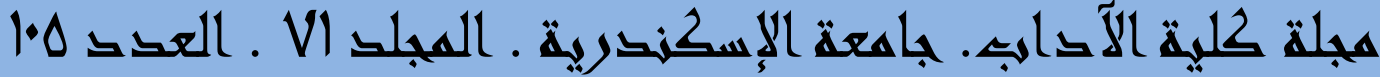

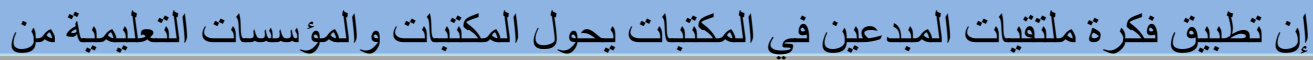

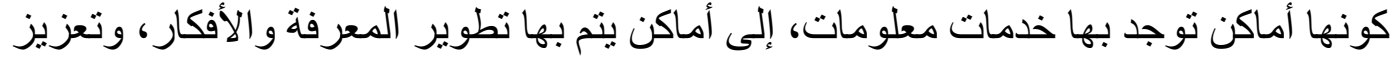

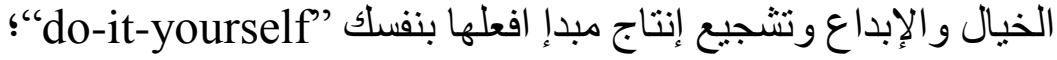

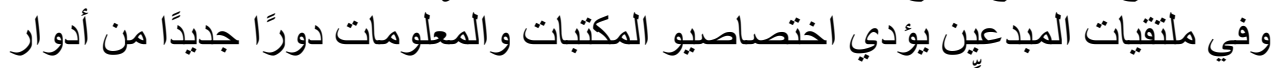

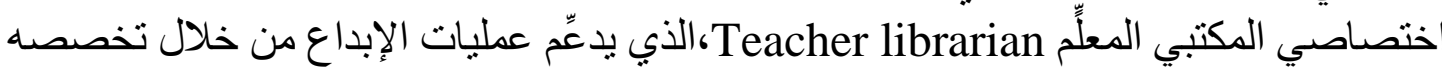

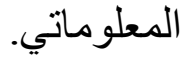

من هنا جاءت الحاجة إلى إعداد هذه الدراسة التي تعد من الدراسات التجريبية القليلة التي اهتمت بملتقيات المبدعين في الوطن العربي.

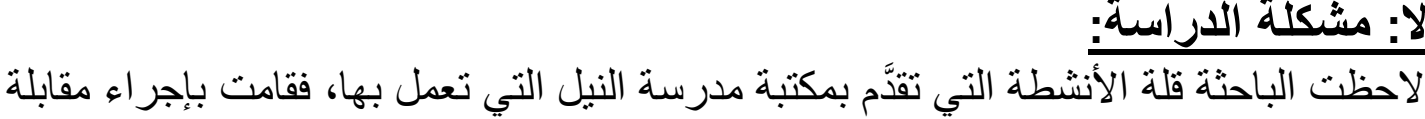

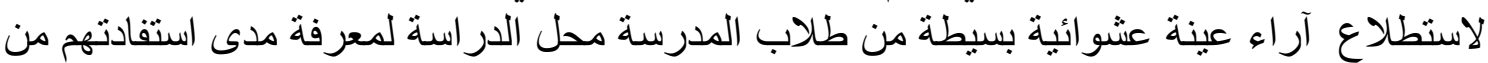

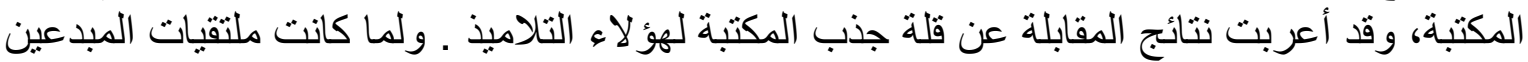

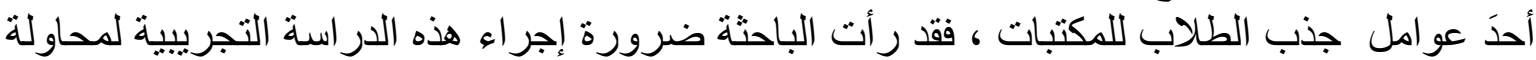

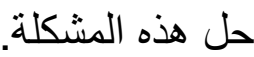

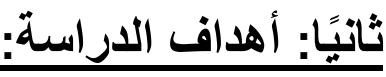

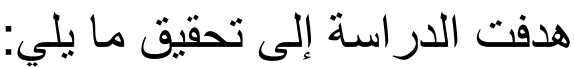

$$
\begin{aligned}
& \text { 1- التعرف على مفهوم ملتقى المبدعين ، و أغر اضهـ. }
\end{aligned}
$$

r- - عرض التجارب السابقة لملتقى المبدعين بالمكتبات و التعلم منها. rـ إبر از علاقة ملتقى المبدعين بالمكتبات المدرسية وإيضاح الأنشطة التي يمكن تقديمها من خلال هذا البرنامج. ع - التعريف بخطوات إنشاء ملتقى المبدعين وكيفية الإفادة منه بالمكتبات لرفع قيمة وقدر المكتبات بين الطلبة و الباحثين. 0ـ استكثاف الفروق بين قدرات التفكير لاى التلاميذ محل الدراسة قبل تطبيق تجربة ملتقى المبدعين بالمكتبة وبعد التطبيق.

ثالثثاً: منهج الاراسة وأدواتها:

استعانت الباحثة لتحقيق أهداف الدراسة،بالمنهيج التجريبي ؛ وذللك لقياس تأثير ملتقى المبدعين

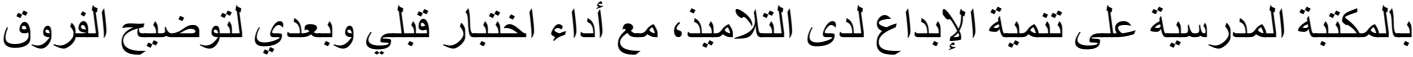
التي تظهر بعد التجربة.

و استخدمت الباحثة التصميم التجريبي ذا المجمو عتين (الضابطة و التجريبية) بقياس قبل بلتيل

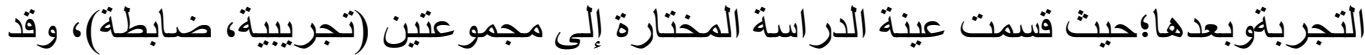

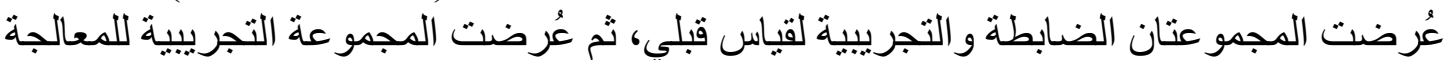

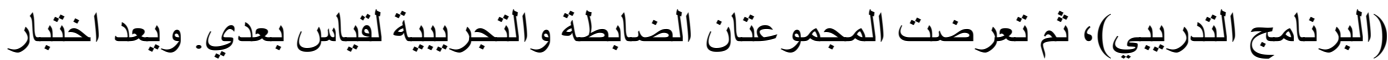

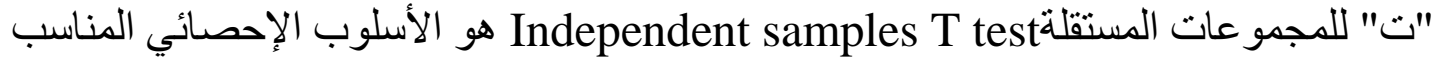
للكثيف عن الفروق بين منوسطي المجمو عتين في المتغير التابع.

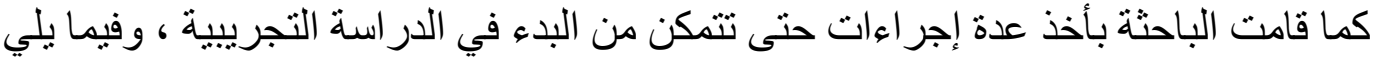




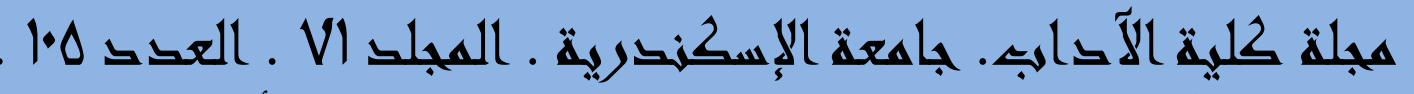

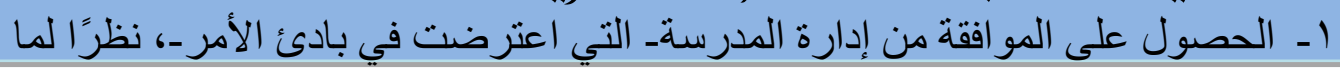

يتطلبه إجر اء الدر اسة من تكلفة مادية، فضلًا عن أن هناك الكثير من الأنشطة الفنية التي تتم خارج المكتبة في بعض المو اد الأخرى.

وكان الحل هو أن يتم دمج هذه الأنشطة مع أنشطة المكتبة واستخدام المو اد والأدوات المتاحة بجانب مشاركة بعض الأدوات من قبل الطلاب.

r- تصميم التدريبات ونماذج أنشطة التفكير الإبداعي التي يمارسها الطلبة خلال فترة الدر اسة، حيث تم الاستعانة ببعض المصادر كالكتب و الدر اسات السابقة الخاصة بأنشطة التفكير الإبداعي، والاطلاع على بعض المو اقع المهتمة بالأنشطة الإبداعية ، وماتشتمل عليه من أنشطة خاصة بكل مرحلة على حدة. بجانب تحضير الأدوات من قبل الطلبة المشاركين و المدرسة أيضًا التي يتم استخدامها في تطبيق بعض الأنشطة. rـ ت تحضير أدوات الدر اسةكالاستعانةبمقياس تورينس للإبداع الثكلي (ب) و الطرق الإحصائية، كالاستعانة بالرزمة الاحصائية للعلوم الاجتماعية (SPSS) لتحليل نتائج الدر اسة.

ع - عرض المقياس على الأستاذ عمرو فتحي، وهو مدرب تنمية المهار ات الذهنية ومستشار نفسي للأطفال و المر اهقين، وذلك في عام VI V. Y، وقد أشار إلى أنه يناسب المرحلة العدرية للأطفال ويلائم هدف الدر اسة، كما أثنار إلى أنه يهدف إلى التعرف على الطلاب الذين لديهم استعداد للإبداع و الابتكار و الذين يميل تفكير هم إلى الأصالة و المرونة و الطلاقة و إدر الك التفاصيل.

ــ الاطلاع على الآر اء القبلية لعينة الدراسة من حيث كيفية استخدامهم للمكتبة من قبل ،

و أنو اعالأنشطة و المسابقاتالتي كانت تقدم،وقد تم ذللك عن طريق أسئلة شفهية من خلال المقابلة الثخصية.فكانتردود الأفعال غير إيجابية ، و أوضحت عدم الرضا من قبل الطلاب

$$
\text { بسبب عدم مشاركتهم في أي أنشطة من قبل. }
$$

7ـ البدء بتطبيق الدر اسة، بحيث تم استخدام المكتبة بالطرق التقليدية للطلاب في المجمو عة الضابطة، وتطبيق أنشطة وأساليب ملتقى المبدعين في المجموعة التجريبية. مع الالتز ام بالوقت المحدد. و استغرقت الدر اسة سنة در اسية كاملة، بو اقع حصة أسبو عيًا لمدة · ع دقيقة. وتم تطبيق أنشطة ملتقى المبدعين داخل الفصول الدر اسية و المكتبة معًا،وذللك لصغر حجم المكتبة. فكانت الفصول الدر اسية للمر احل كبيرة العدد، و المكتبة للمر احل صغيرة العدد. فالمكان ليس هو الغرض الأساس، لكن تطبيق و إجر اء كافة الأنشطة هو الذي يجب التركيز عليه. 


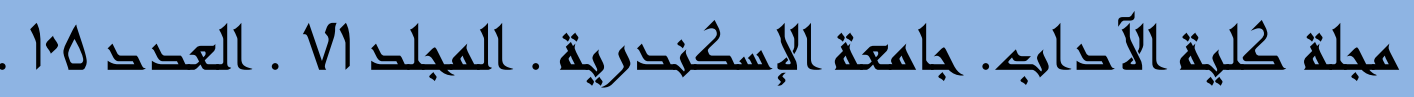

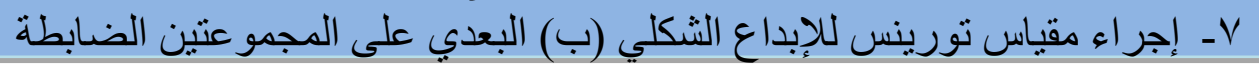

$$
\text { و التجريبية. }
$$

ᄉ- جمع البيانات وتحليل النتائج ومقارنتها بالدر اسات السابقة وكتابة التوصيات.

\section{وقد قامت الباحثة بالاستعانة بالأدوات التالية لإجراء الاراسة:}

ا و. مقياس تورينس Torrance اللتفكير الإبداعي الثكلي (ب).

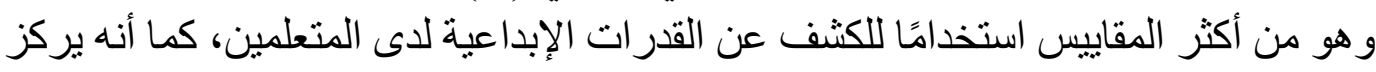
على قدر ات الطلاقة، المرونة، الأصالة و التفاصيل.

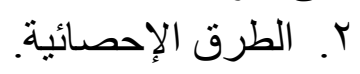

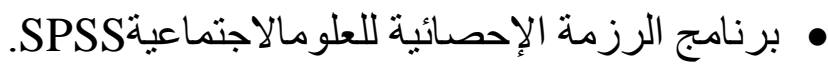

$$
\begin{aligned}
& \text { • اختبار الصدق. } \\
& \text { • معامل ثبات كرونباخ ألفا. } \\
& \text { • اختبار ت Test. } \\
& \text { • • ل اختبار مربع كاي. } \\
& \text { • اختبار أنوفا. }
\end{aligned}
$$

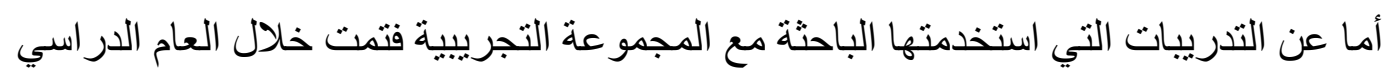

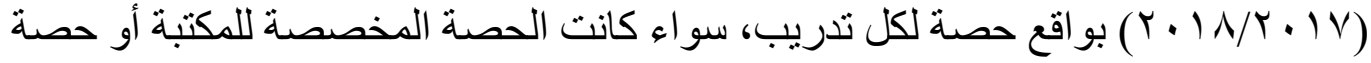

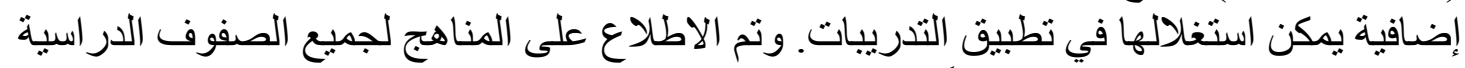

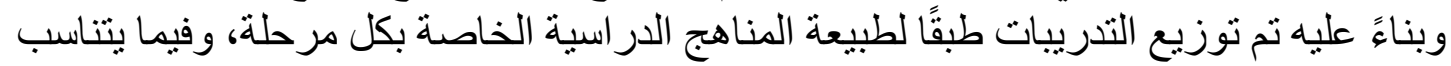

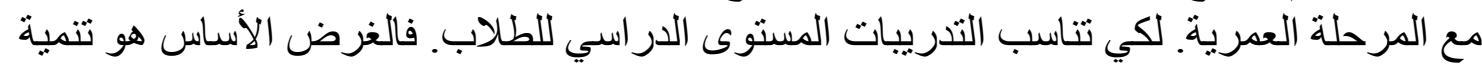
الإبداع لديهم وليس تعقيدهم.

ولقد تتو عت الأنشطة التدريبية لتناسب عناصر الإبداع كالطلاقة، المرونة، الأصالة

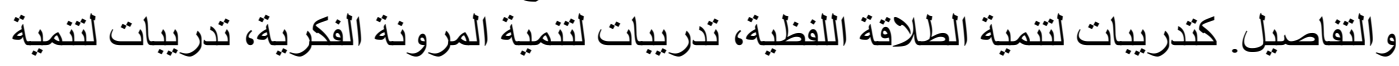

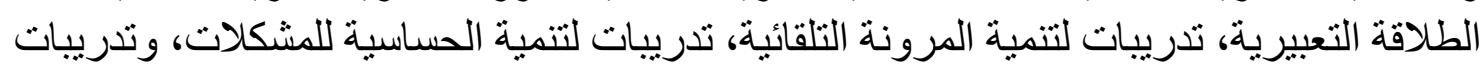

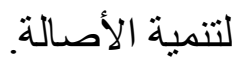

\section{ررابعًا: فصول الدراسة:}

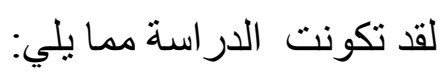

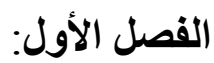

تناول الإبداع بمفهومه الثامل والابتكار أيضًا، وأوضح الفرق بينهما.

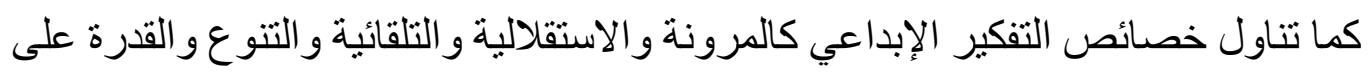

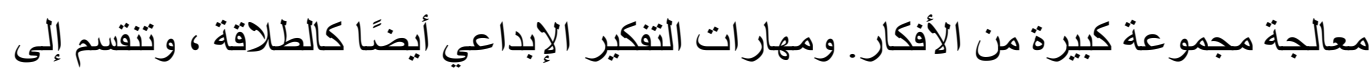

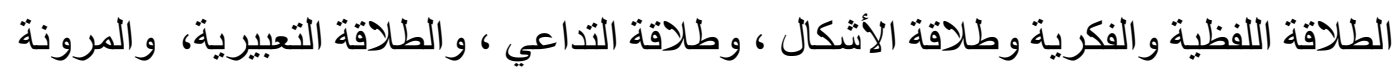
و الأصالة و التوسع و الحساسية للمشكلات. 


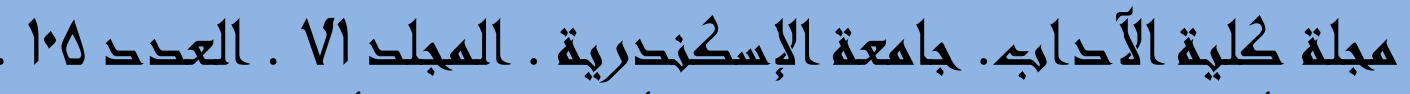
وتتاول أيضًا ما يعيق الإبداع ؛ فالإبداع ظاهرة تتأثر بعدة عو امل كالأسرة و المجتمع و المعلم.

لذلك تم ذكر و عرض طرق تعزيز الإبداع كما وضحها تورينس كاحتر ام أسئلة الطلاب وخيالاتهم.

ثم بعد ذلك تناول مصطلح ملتقى المبدعين و علاقته بالمكتبات، فهو استعارة لبيئة تعليمية

فريدة تشجع على اللعب و الاستكثاف المفتوح للجميع، كما أنه و احد من أكثر الممتلكات القيمة للمكتبة. ويضم جميع الفئات العمرية. ويهتم بمشاركة التكنولوجيا كالطابعات ثناثية الأبعاد وقو اطع الليزر.

كما عرض طرق إنشاء ملتقى المبدعين بالمكتبات، و الاعتبار ات التي يجب الأخذ بها عند التخطيط لإنشاء ملتقى المبدعين.

الفصل الثاني: استعرض هذا الفصل نماذج لملتقيات المبدعين في شتى أنواع المكتبات في العالم؛ وفي الفصل التالي تتحدث الباحثة عن الدر اسة التجريبية التي أجرتها لتنمية الإبداع لدى مكتبة مدرسة النيل الحديثة للغات بالإسكندرية.

الفصل الثالث: تناول هذا الفصل مجتمع الدر اسة ، حيث تكون من تلاميذ المرحلة الابتدائية

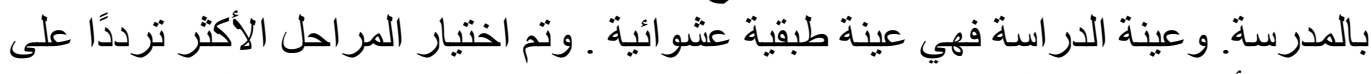

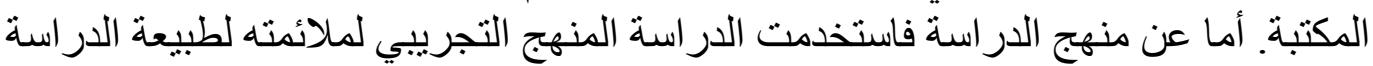

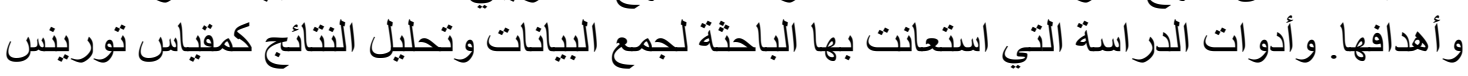
للتفكير الإبداعي.

كما عرضت الباحثة نماذج لأنشطة التفكير الإبداعي التي تم تطبيقها مع الطلاب كالأنشطة

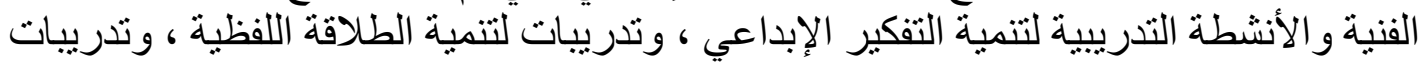

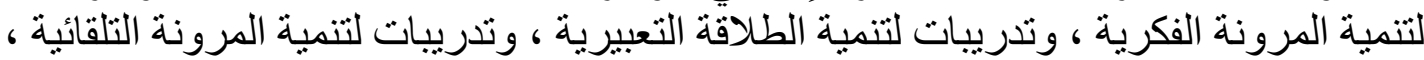

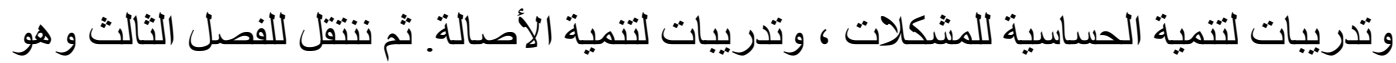
تحليل للار اسة التجريبية.

الفصل الرابع: تحدث هذا الفصل عن تفاصيل الدراسة التجريبية لدور ملتقيات المبدعين في تنمية الإبداع لدى مكتبة مدرسة النيل الحديثة للغات بالإسكندرية ، وفي الصفحات التالية يأتي الحديث عن نتائج وتوصيات الدر اسة.

\section{خامسًا :نتائج الاراسةة: \\ فيما يلإي أهم النتائج التي توصلت إليها الارسة:ة}

ا - تتنوع الأنشطة بملتقيات المبدعين بين أنشطة يدوية وأنشطة إلكترونية، و أدوات

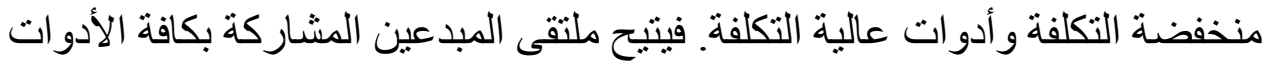

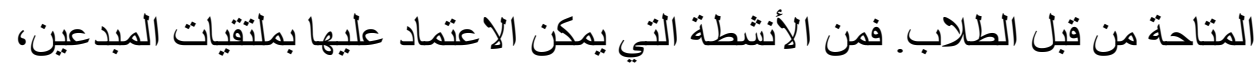
أنثطة التفكير الإبداعي كتدريبات لتنمية الطلاقة اللفظية، وتدريبات لتنمية المرونة 


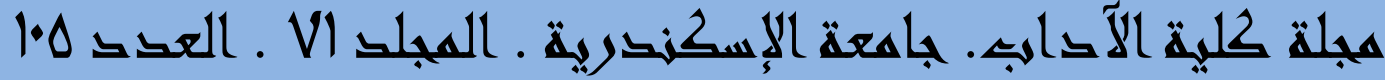

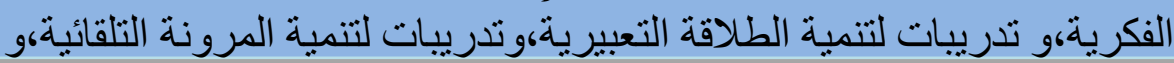

تدريبات لتنمية الحساسية للمشكلات وتدريبات لتنمية الأصالة.

r ـ كانت نتائج إنشاء ملتقى المبدعين في مساعدة التلاميذ عينة الدراسة على ترقية قدر ات التفكير ، كالتالي:

تبين وجود فروق ذات دلالة إحصائية بين المجمو عة التجريبية و المجمو عة الضابطة لصالح المجمو عة التجريبية.

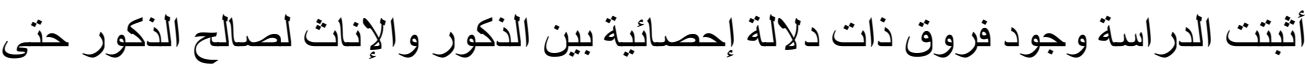

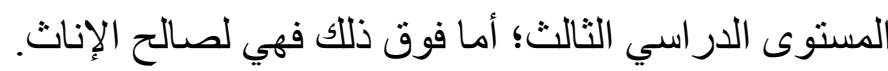

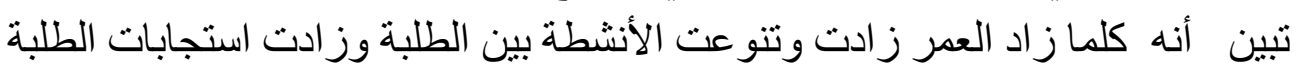

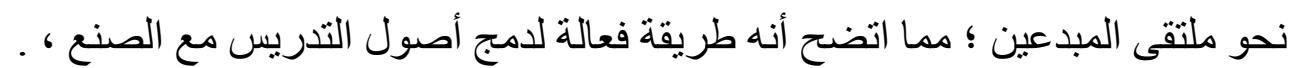

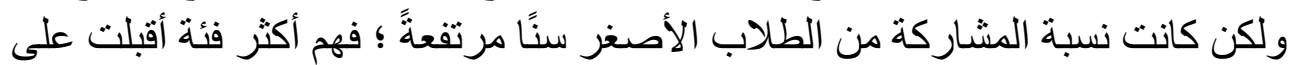

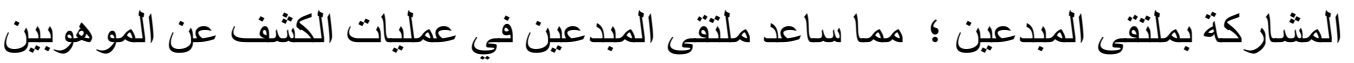

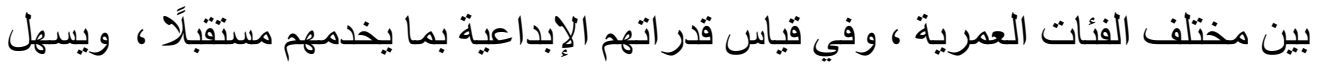
عليهم إفادة أنفسهم ومجتمعاتهم. توجد دلالة إحصائية مذكورة في علاقة نتائج الاختبار البعدي ـ في المجموعة التجريبية ـ

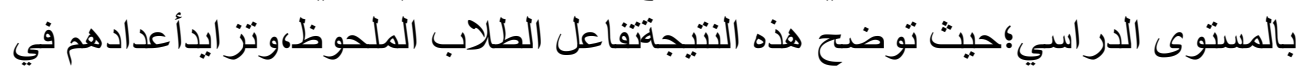

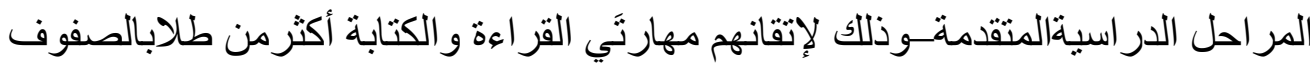

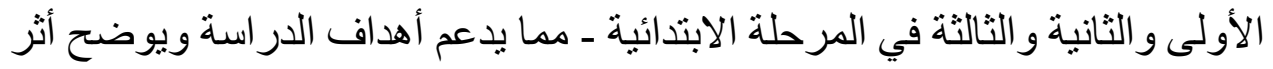
إنثاء ملتقى المبدعين بالمكتبة محل الار واسة.

وبشكل عام، فلقد أثبتت النتائج التي توصلت إليها الباحثة مدى إسهام ملتقيات المبدعين ودور ها في تتمية الإبداع لدى التلاميذ من خلال توفير العناصر المادية اللازمة لمحاولة تنمية الإبداع الفكري للتلامبذ، كما توصلت إلى أن هنالك علاقة بين ملتقيات المبدعين بالمكتبات المدرسية ، وتتمية الإبداع لدى التلاميذ في المرحلة الابتدائية، كما أنها إضافة لقيمة المكتبة. سادسًا:توصيات الدراسة:

\section{في ضوء نتائج الدراسة اقترحت الباحثة عدة توصيات فيما يلي ذكرها:}

ا. . ضرورة إتاحة ملتقيات المبدعين في المكتبات على اختلاف أنو اعها.

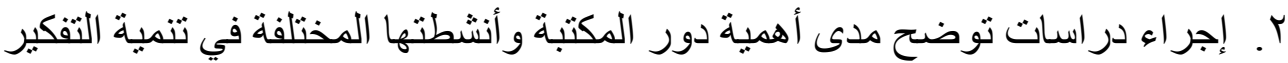

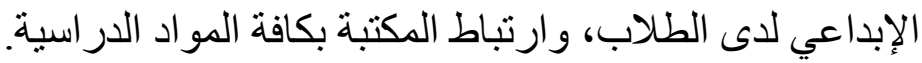
ץ. هنالك حاجة إلى مر اقبة ملتقيات المبدعين لفترة أطول، وتقديم رؤى قيمة في مجال الصنّة الصنع. وتنويع عينة البحث للتعرف على البى احتياجات ومتطلبات بئئة الصنع.

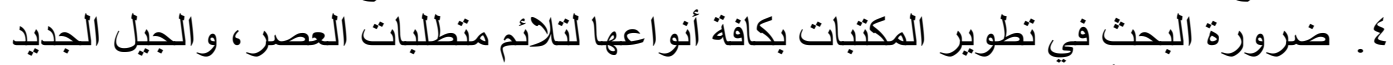

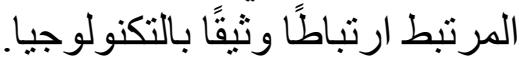

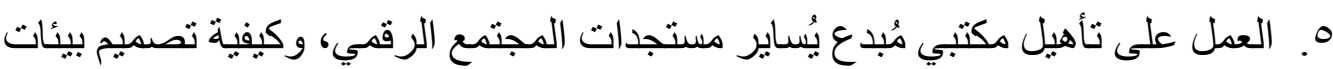

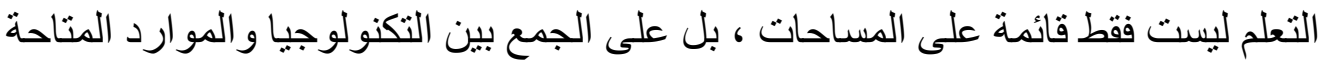

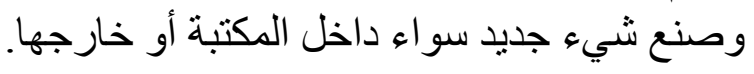




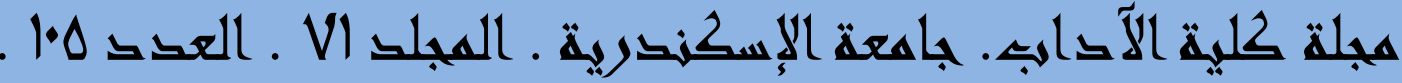

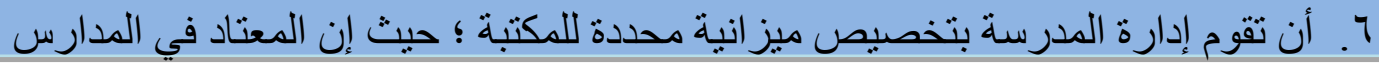

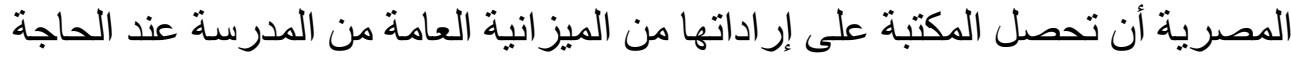
فقط ، وليس بشكل منتظم. V. ضرورة استكثناف اهتمامات الطلاب، و البدء بإنشاء ملتقى المبدعين،من أجل بناء مجتمع

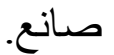
^. تعديل سياسة الافتناء بالمكتبات المدرسية بما يتناسب مع الإبداعات الفكرية لتلاميذ المدرسة، كاقتناء المجسمات و الرسوم التوضيحية.

و إضافةً إلى ما سبق، فهناكك بعض الأساليب المقترحة للتظلب على معوقات الإبداع في المجتمع

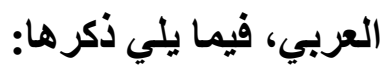

هناك حاجة إلى نهضة شاملة، تعتمد على ترسيخ ثقافة الابتكار في شتى المؤسسات التعليمية،

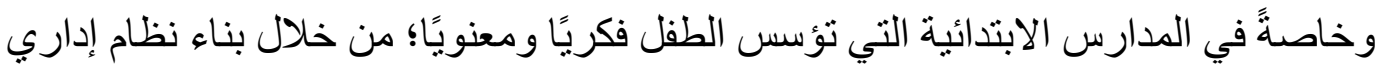
داعم للابتكار يهيئ المناخ المناسب لتمكين العاملين بهذه المؤسسات التعليمية من توليد الأفكار التعليمية المبدعة، وتحو يلها إلى ابتكار ات تعليمية. إعداد دراسات متعقةة للتعرف على كافة العو امل التي تعرقل نمو القدر ات الإبداعية.

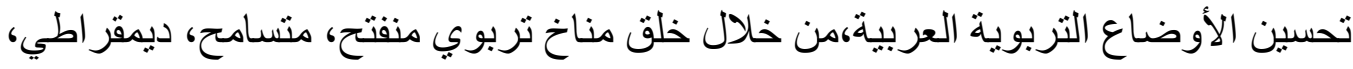
يتقبل النقا، ويقدر التفكير الإبداعي، كما يشجع التعلم الذاتي.

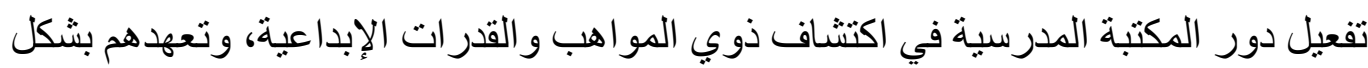
مبكر بالر عاية اللازمة وتوفير الإمكانات و الخدمات لذلك؛من أجل الوصول إلى مجتمع سعيد ومزدهر يربي أبناءه على صناعة مستقبلهم،من خلال مكتبات مدرسية مبتكرِك. تفعيل دور المكتبة في تتمية مهار ات الابتكار للمستفيدين من المكتبات المدرسية، من خلال دعمها إداريًا، ومعنويًا ، وماديًا. تفعيل دور المكتبات المدرسية في تطوير التعليم من خلال تطوير عقليات مديري ومدرسي وتلاميذ المدارس.

تحويل المكتبات الدرسية العربية إلى ملاعب للفِكر تمنح السعادة لمستفيديها، مما يعيد التناميذ إلى هذه المكتبات التي انصرف عنا الكثيرون منهم. تطوير الجو الدراسي التقليدي بالانتقال من الفصل الدراسي إلى الحياة الحقيقية من خلال

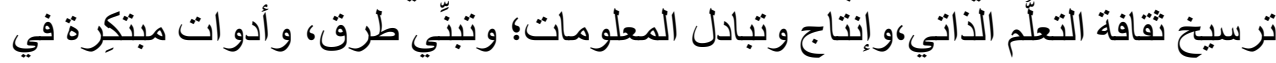

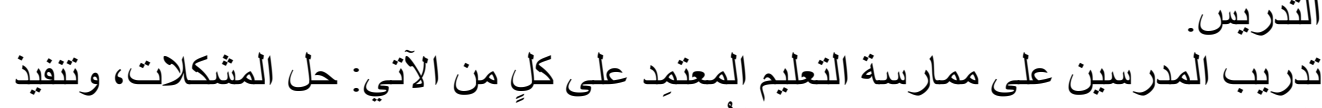

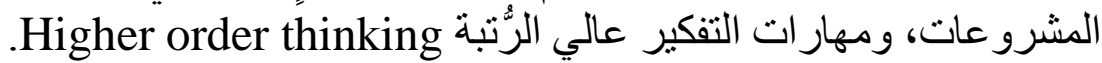
تدريب اختصاصيي المعلومات بالمكتبات المدرسية على ممارسة تقنيات الابتكار المختلفة. 


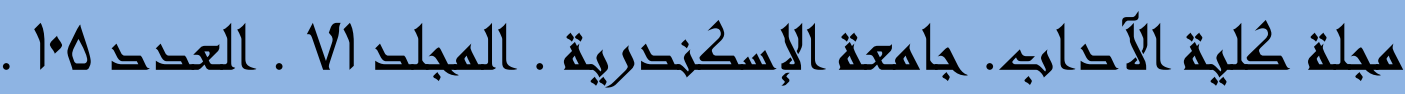

تدريب اختصاصيي المعلومات بالمكتبات المدرسية على ممارسة الطرق المختلفة للإبداع في .

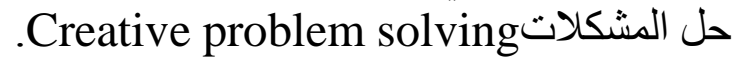
دعوة الأفر اد المقتدرين و المؤسسات الاقتصادية لتبني مشاريع وبر امج خاصة لتنمية القدرات

\section{الاليل المقترح من قبل الباحثة لملتقى المبدعين بالمكتبات المدرسية}

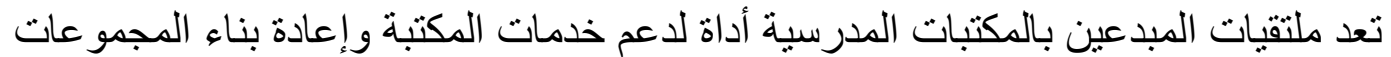

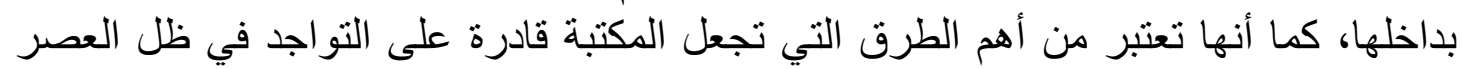
الرقمي الذي يبحث عنه الطالب ، بل ويتو اجد بداخله أغلب وقته. كما أنها تجعل المكتبة مكانًا

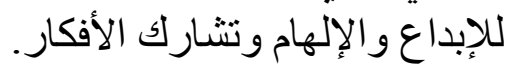

وبالر غم من أن ملتقى المبدعين إضافة للمكتبة المدرسية، بل للمدرسة ـ لأنه يخدم مختلف المواد الدراسية ـ إلا أن علينا أن نتطرق إلى الى العقبات التي تواجه إنشاء أو تطبيق ملتقيات المبدعين "Makerspaces" بالمكتبات المدرسية. كعدم موافقة إدارة المدرسة بتطبيق مثل هذه اهنه

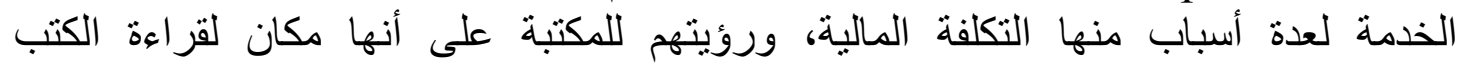

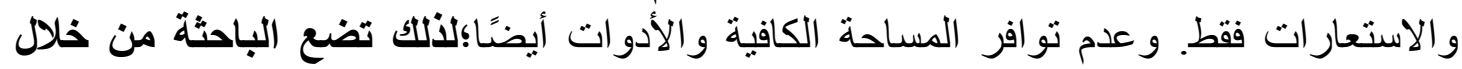
تجربتها عدة خطوات لإنشاء ملتقى المبدعين بالمكتبة المدرسية. فيما يلي:

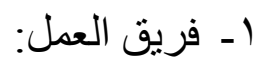

يجب التأني في اختيار فريق العمل ؛ فيجب اختيار من يتحلى بالصبر، ويتسم بالدقة

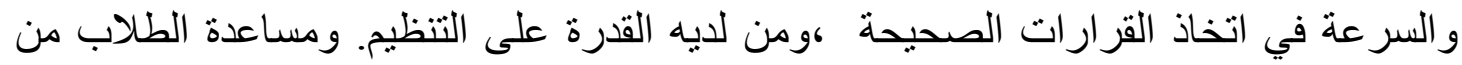
خلال الإجابة عن أسئلتهم، ومشاركتهم العمل في أثناء أداء أنشطة ملتقى المبدعين.

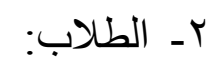

ينبغي تحديد الفئة العمرية أو الصفوف الدراسية التي ستشارك في ملتقى المبدعين. هل سيكون مقتصرًا على فئة عمرية محددة أم مفتوحًا للجميع؟ فتحديد هذا العنصر سيساعد في اختيار

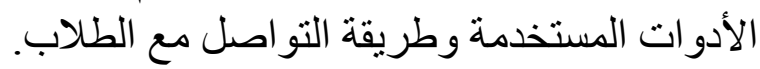

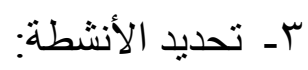

يقوم اختصاصي المكتبة بوضع أو تحديد الأنشطة التي سيقوم بها مع الطلاب داخل ملتقى الأى

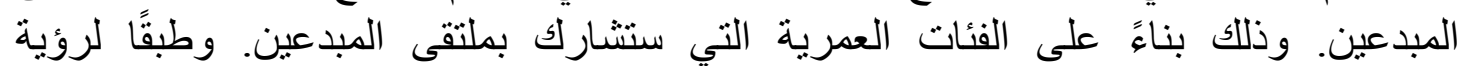
اختصاصي المكتبة فيما يتناسب مع المكتبة المدرسية.

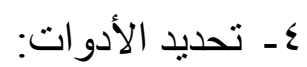

تحديد الأدوات و المواد المستخدمة بأنشطة ملتقى المبدعين، فلكل نشاط أدواته الخاصة.

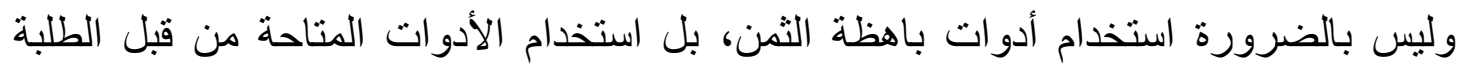

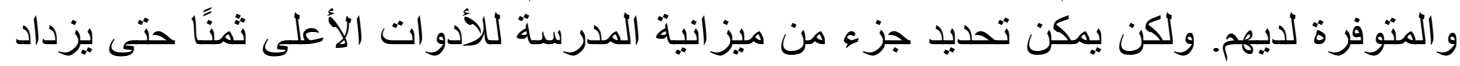

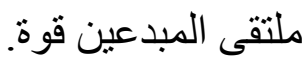
ــ تجربة الأنشطة: 


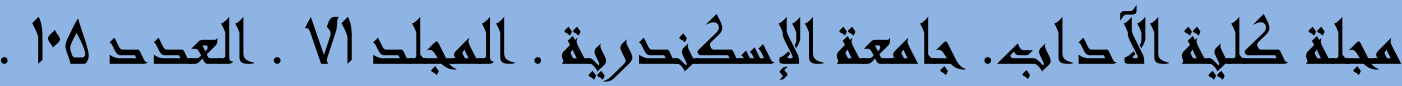

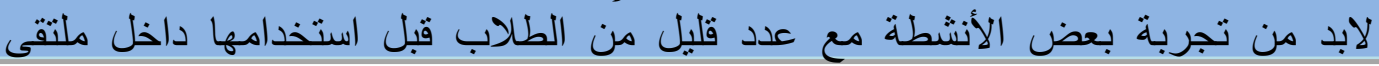

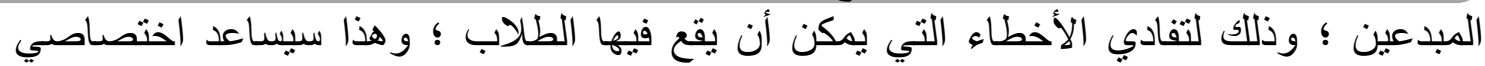
المكتبة على الإلمام و الإحاطة بمميز ات و وليوب كل كل نشاط.

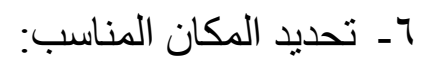

تحديد الدكان المناسب وليس السساحات؛ فليس بالضرورة اختيار المساحات، بل تحديد

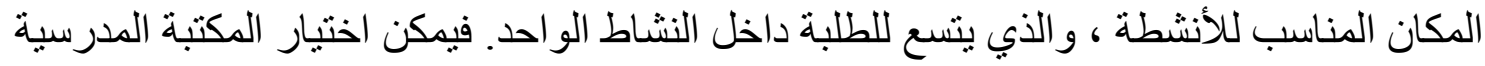

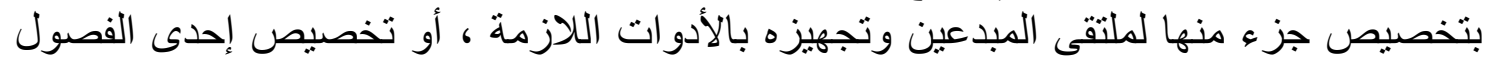

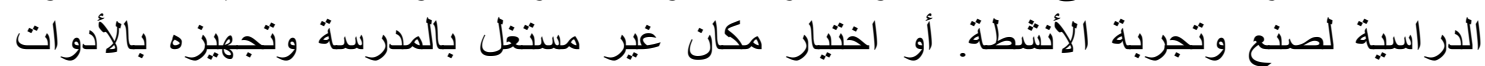

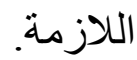

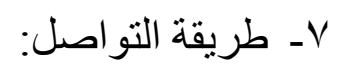

تحديد طرق التواصل مع فريق العمل والطلاب من أهم عوامل النجاح. أصبح الإنترنت التهاء

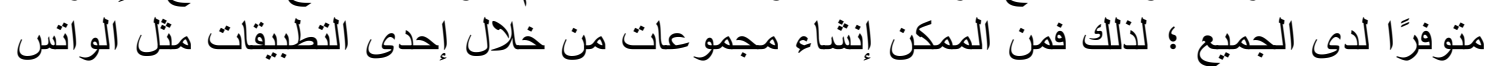

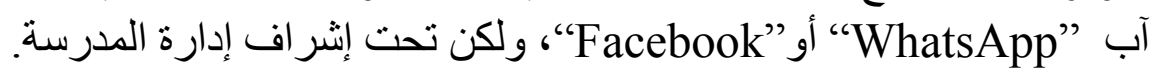

$$
\text { ^ـ الإعلان عن الأنشطة المتاحة: }
$$

بعد تحديد طريقة التواصل مع الطلاب خارج نطاق المدرسة، يأتي الإعلان عن الأنشطة

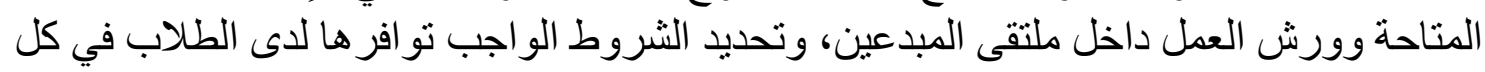
نشاط، وكذلك مو اعبد إجر اء كل نشاط.

$$
\text { 9- آراء المستفبدين: }
$$

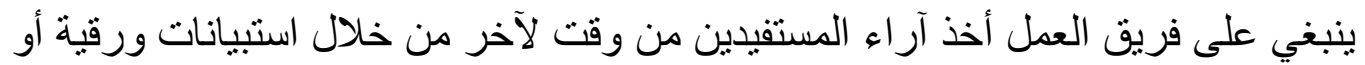
شفهية. و العمل على تجديد وتطوير ملتقى المبدعين بناءً على آر اء المستفيدين.

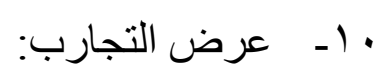

يعد عرض تجارب الطلاب المشاركين بملتقى المبدعين من عوامل مكافأتهم وتحفيز

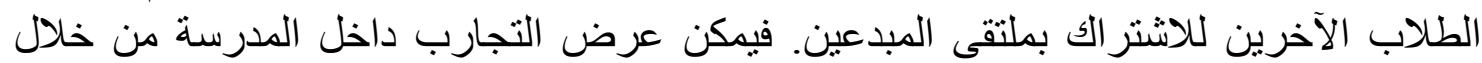

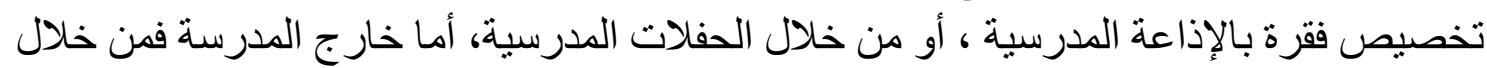

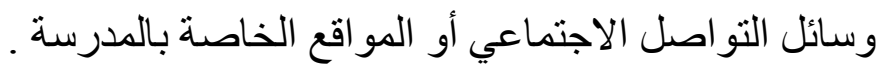




\title{
العرض الثالث
}

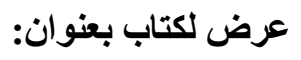

" لون حياتك بفكرة : دليلك العملي البسيط إلى ترقية قدرات عقلك،وحل مشكلاتك

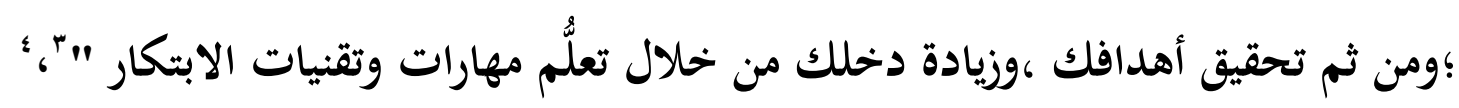

\author{
إعداد \\ محمد عبد الفتاح كامل \\ موجًّه المكتبات المدرسية بمحافظة شمال سيناء \\ دكتوراه في المكتبات و المعلومات ـكلية الآداب جامعة المنوفية
}

تمهيا

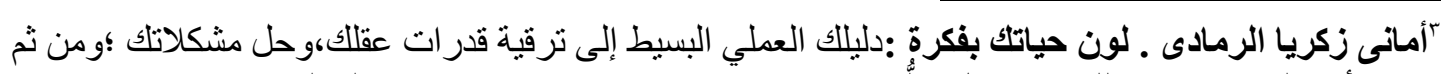

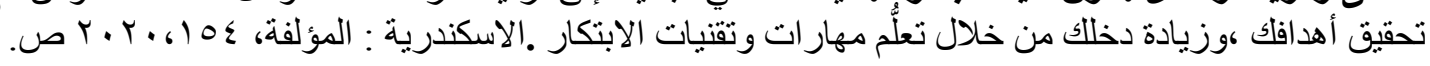




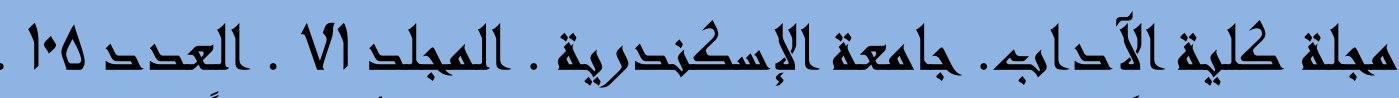

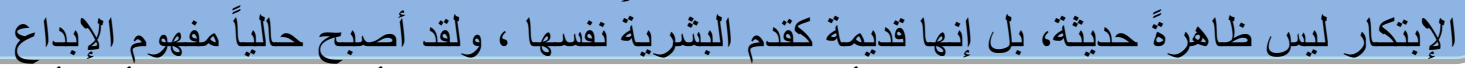

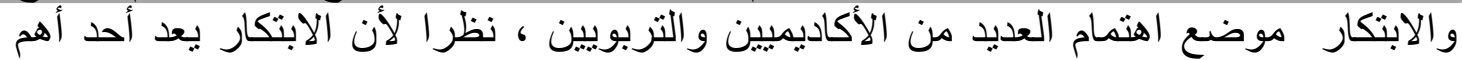

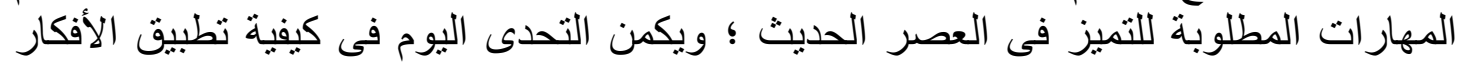

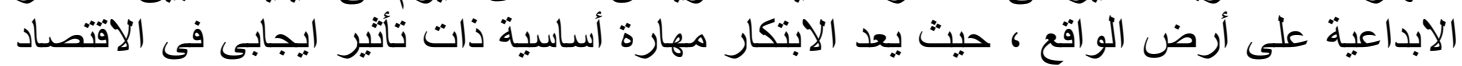

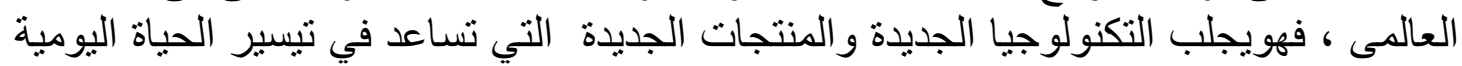

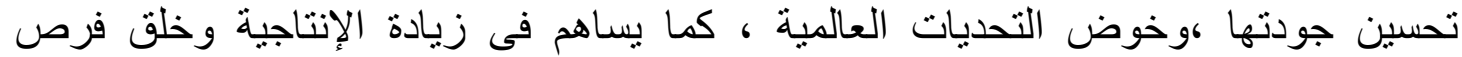

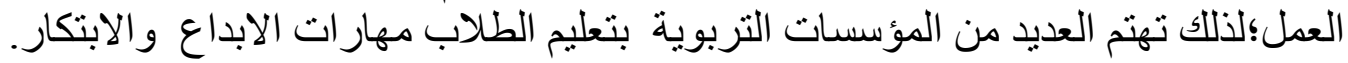

"من ناحيةٍ أخرى، فإن العقل هو أعظم نعم الله تعالى على الإنسان، وهو أهم أعضاء الجسد،

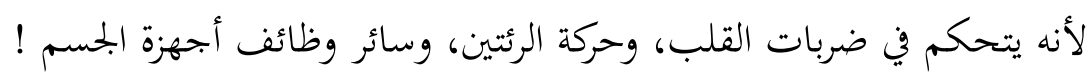

لذا فإنه من الضروري أن يحرص الإنسان على أن يظل عقله يعمل في أفضل ظروف ممكنة،

سواء من خلال التغذية السليمة،أو الظروف المعيشية الصحية، أو من خلال تدريبه وترقية قدراته بشتى لإنى

وكما قال آيدو كوينكان Idowu Koyenikan :" العقل مثل العضلة - كلما قُمتَ بتمرينها، كلما

زادت قوتها، وكلما زادت قدرتها على التمدد" !

"The mind is just like a muscle - the more you exercise it, the stronger it gets and the more it can expand"

ولعل أهمية العقل السليم تتضح حين نفكر كيف ستكون الحياة إذا لم نستطع أداء الوظائف اليومية

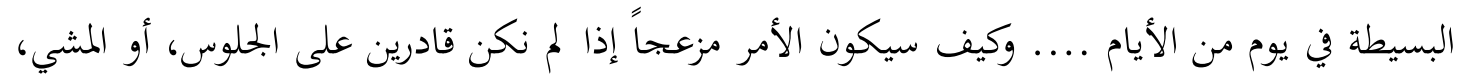
أو الاستعداد لأداء مهامنا الرئيسة في الصباح بدون مساعدة من قريب أو صديق !!!!"

من أجل هذا اخترت للقارىء الكريم هذا الكتاب الذى يعد دليلاً عملياً يهذف الى تنشيط ملَكات

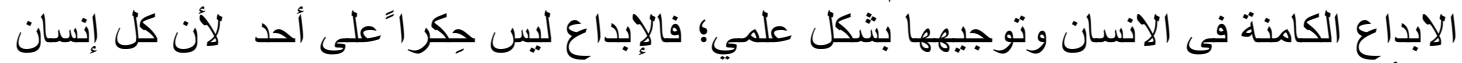
مبدع بالفِطرة . كما يساهم هذا الكتاب في المساعدة على تحويل الأفكار المُبدعة للانسان إلى منتجات،

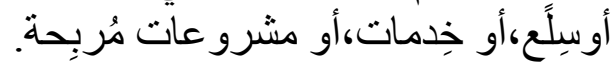

\section{محتوى الكتاب}

يتكون الكتاب الأي بين أيدينا من ثلاثة أبواب، يحتوي كل منها على فصلين ، وفيما يلي

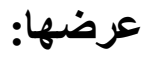

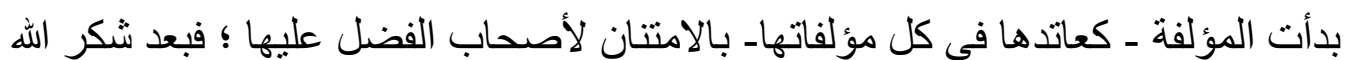

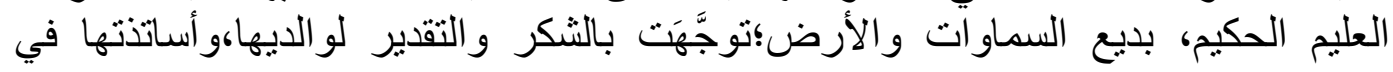
Dr. Noordin تخصص المكتبات والمعلومات ،ثم للدكتور/نور الدين شهاب الدين بـو 


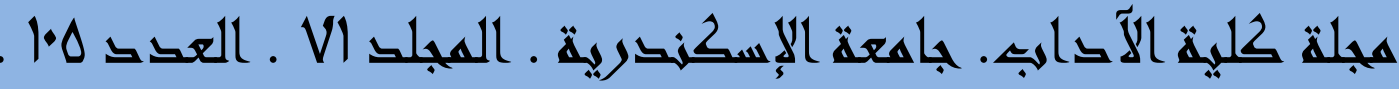

هhehabuddeen تعلَّمَت منه التدريس الإبداعي،والأستاذ/عبد الحميد جاسم البلالي الذي أفَادت من كتابه المعنوَن : "الإبتكار طعمّ آخر للحياة".

كما توجهت بالشكر والتقدير إلى زملاء مهنة المكتبات والمعلومات الذهياه الذين يجتهدون

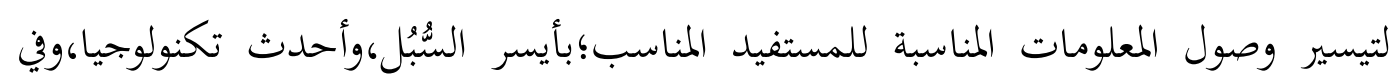
الوقت المناسب.

وختمت بالشكر والتقدير لكل من يحب التميُّز، ويطمح إلى تنمية قدراته، وتطوير

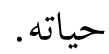

وقبل أن يبدأ القارىء في الاطلاع على محتوى الكتاب ،قامت المؤلفة بتمهيد أوضحت فيه

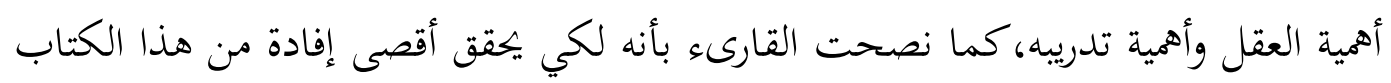

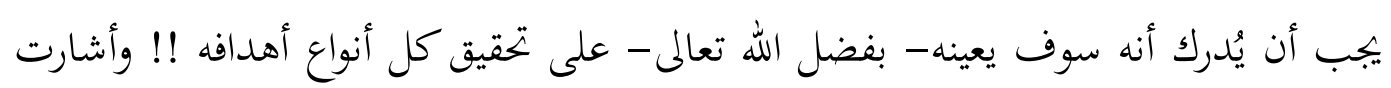

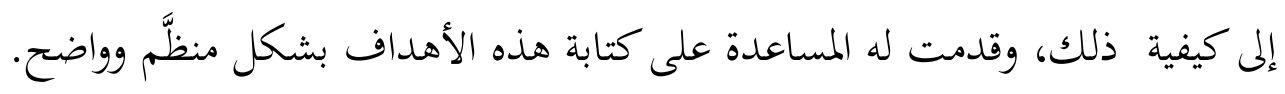

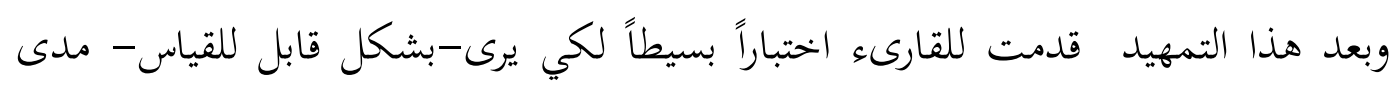

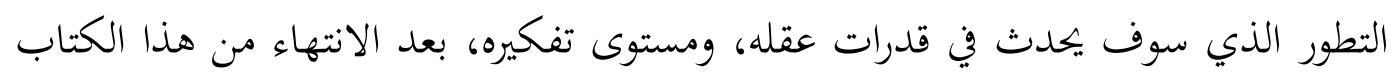
، وإجراء نفس الاختبار ، مع مقارنة النتائج.

\section{الباب الأول: و عنو انه : "مرِّن قدرات عقلك"}

بدأ هذا الباب بالفصل الأول وعنوانه: "صالة ألعاب العقل" ، وهو مكان لممارسة الرياضة العقلية من أجل

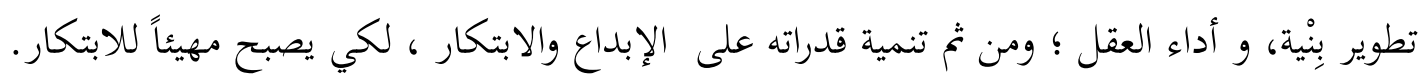
وفيه قدمت المؤلفة العديد من التمارين العقلية والرياضية التي تعين على زيادة الانتباهوتنمية قوة الملاحظة،وزيادة التركيز

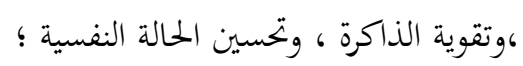

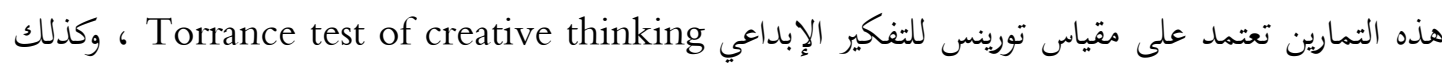

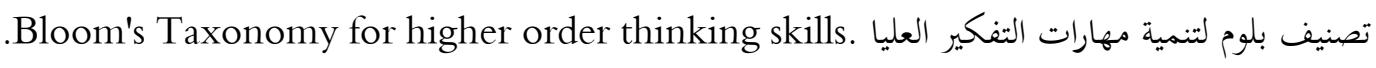
كما ساهم هذا الفصل في اكتساب المعرفة حول أفضل العادات اليومية والغذائية لصحة العقل والذاكرة 


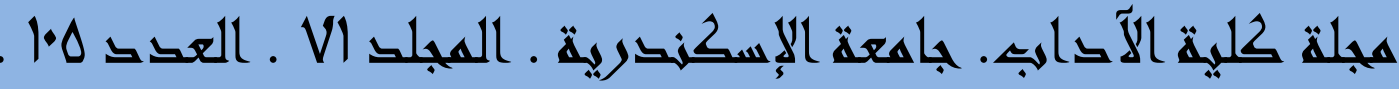

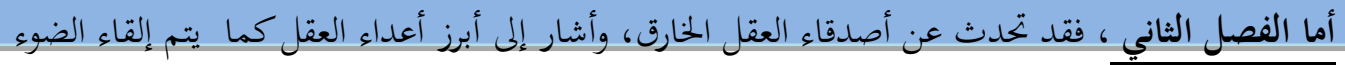

على كيفية قيام الإنسان بتحرير القوى الكامنة لعقله، فضلاً عن إكسابه المعرفة حول أفضل العادات اليومية العاديا

والغذائية لصحة العقل والذاكرة .

وأخيراً انتهي هذا الفصل بالإشارة إلى صفحة علمية بحانية متاحة عبر فيسبوك تتم بتدريب وتنمية إمكانات العقل، وشحن طاقته؛ مما يترتب عليه ترقية مهارات التفكير، وتقوية الذاكرة، وتنمية قدرات الابتكار.

\section{الباب الثاني: وعنوانه : "الإبداع والابتكار"}

$$
\text { انقسم هذا الباب إلى فصلين : }
$$

\section{الفصل الأول، بعنوان : الإبداع والابتكار: تعريفات ومفاهير.}

أوضح هذا الفصل الفرق بين الإبداع والابتكار ، ثم قدم تمرينات لتنمية مهارات التفكير عالي الرتبة Higher

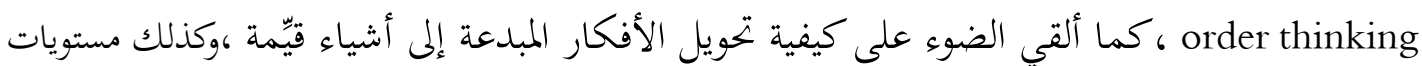

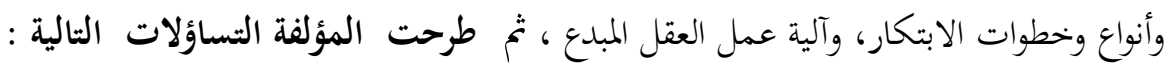

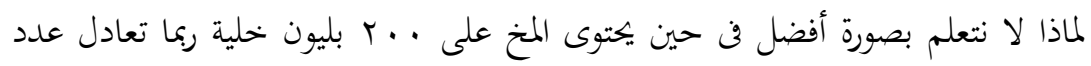

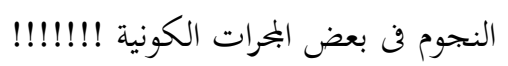

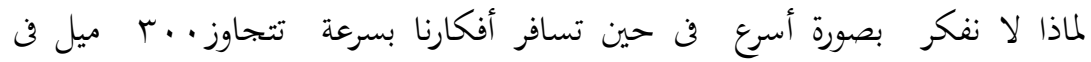

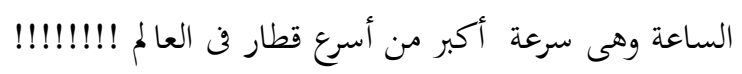

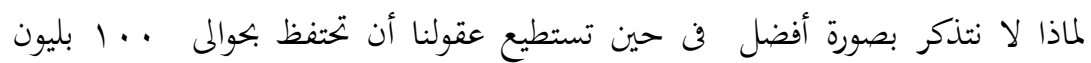

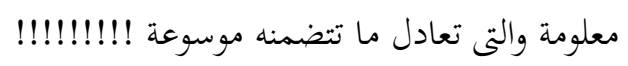

لماذا لا نفهم بصورة أفضل فن حين تختوى عقولنا على أكثر من تريليون وصلة متملة

$$
\text { (و (و جاءت الإجابة على كل هذه التساؤلات ،وهي: }
$$

كل هذا بسبب أن معظمنا لا يستخدم سوى قدر ضئيل من قواه العقلية ))

بعد ذلك تمت الإشارة إلى كيفية استخدام القدرات الكاملة للعقل بدلاً من استخدام جزء منها فقط ؛ من خلال تمارين

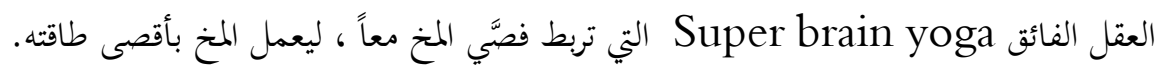

$$
\text { كما ناقش هذا الفصل النقاط التالية : }
$$

*مكوّنات الابتكار: مثل الفضول والشجاعة وقلة الخوف من الفشل ومهارات التفكير النقدى وتوافر الدافع

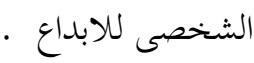

*معوقات الابتكار: مثل الحوف من التغيير ، والخوف من فشل التجربة الجديدة والشعور بالتهايد و شعور البعض

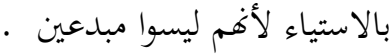
*كيفية إعداد العقل للابتكار:من خلال التأمل والرياضة وتنمية القدرة على الربط بين الأشياء : 


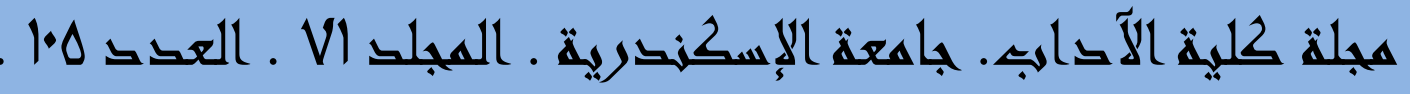
أخطوات التى تساعد على تنمية الأفكار الابداعية. * كيفية تقييم الأفكار المبدعة . ثم انتهى بتمرينات لتنمية مهارات التفكير عالي الرتبة . الفصل الثانى ، بعنوان: أدوات وتقتيات الابتكار : وفيه أوضحت المؤلفة - بأمثلة كثيرة-إحدى النقاط الهامة وهى أدوات وتقنيات الابتكارالتي تعين- بشكل عملي-

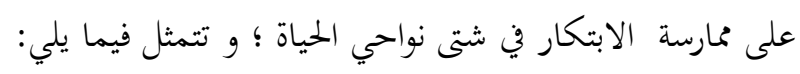

$$
\begin{aligned}
& \text { - - ملخروج عن المألوف أو كسر القاعدة . } \\
& \text { - محاكاة الكائنات الحية ل } \\
& \text { - - الارتجال وتغيير الإطار. } \\
& \text { - - التفكير من وجهة نظر الآخرين . } \\
& \text { - - التفكير فيما يؤلم ويُزعِج . } \\
& \text { - }
\end{aligned}
$$

Osborn's check list قائمة أوسبورن ويتميز هذا الفصل بالصور التوضيحية التي تعين على فهم وتطبيق التقنيات المذكورة.

\section{الباب الثالث: حل المشكلات بطرق إبداعية}

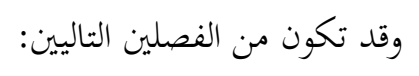

\section{الفصل الأول : حل المشكلات بطرق إبداعية:}

وفيه طرحت المؤلفة أسلوباً جديداً من أساليب تيسير الحياة وتلوينها بألوان جديدة ومفيدة ؛ ألا وهو

اكتساب مهارة حل المشكلات بطرق إبداعية؛ فمهدت للقارىء بملاحظات قبل الإقدام على حل المشكلة، تم ألقت الضوء على أهمية اكتشاف أسباب المشكلات ، وعرضت طُورِقاً عديدة لذلك.

\section{الفصل الثانى: أبرز الطرق للإبداع فى حل المشكلات :}

في هذا الفصل عرضت المؤلفة أبرز الطرق للإبداع في حل المشكلات؛وهي: تحويل المشكلة الى سؤال،و تحويل المشكلة الى خيال ، وإعادة تصميم المشكلة ،وطريقة إثارة الغضب أو التحدي.

وفي نهاية هذا الباب قدمت المؤلفة اختباراً لقياس مدى النطور الذي حدث في عقل القارىء، وفي مستوى مهارات التفكير لديه بعد الإفادة من هذا الكتاب.

وبعد، فان الكتاب الذي بين أيدينا يفيد كثير اً فى مسـاعدة الإنسـان على تحريرمشـاعره السلبية

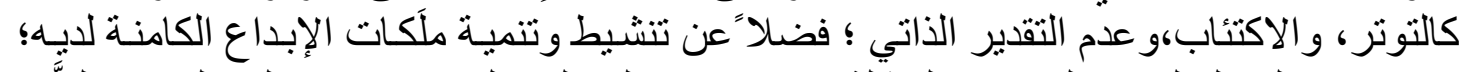

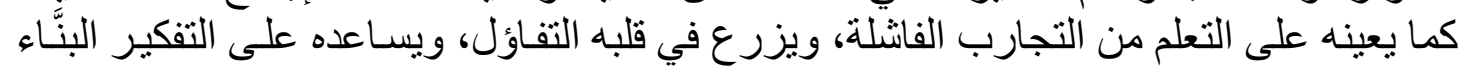




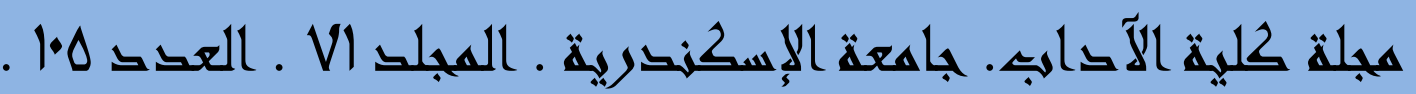

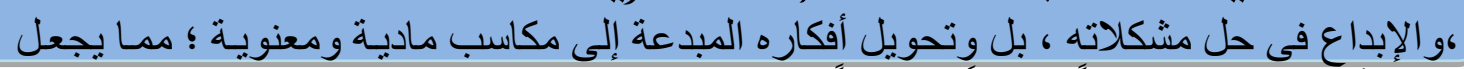

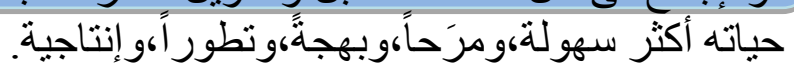

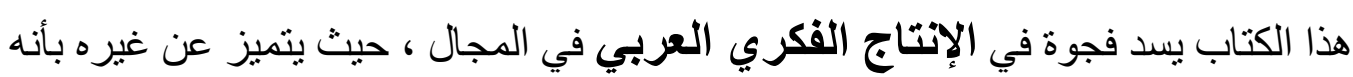

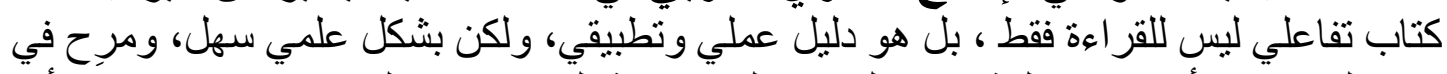

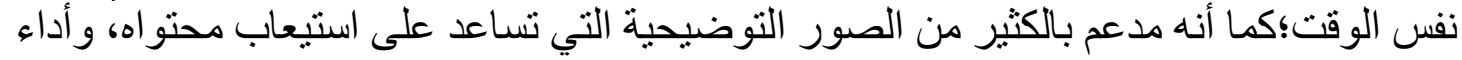

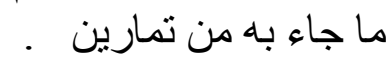

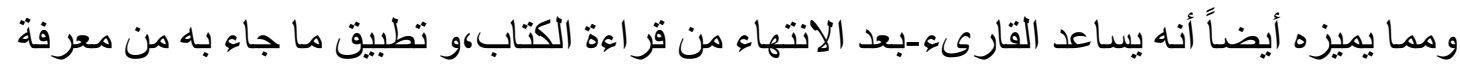

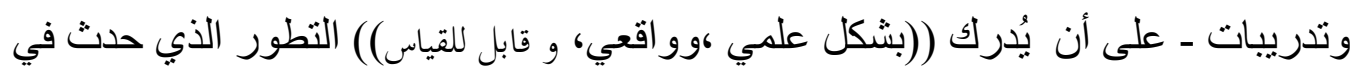

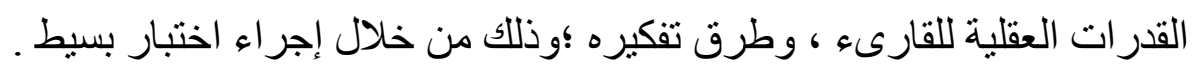

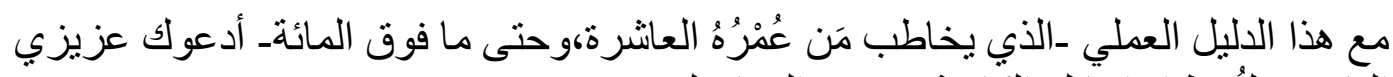

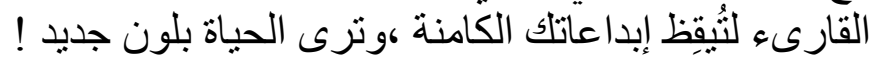

